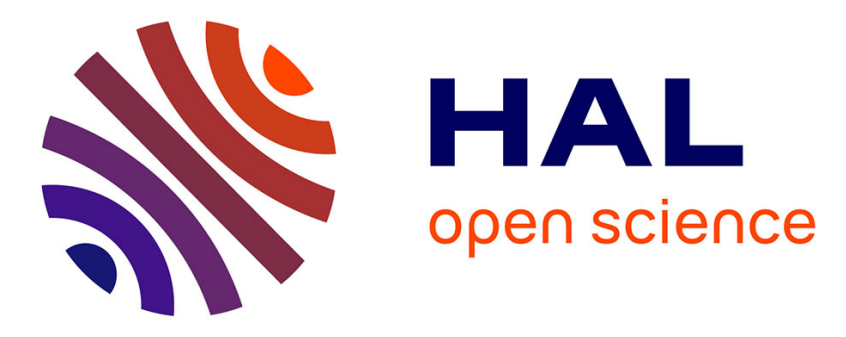

\title{
Design, synthesis and biological evaluation of gentiopicroside derivatives as potential antiviral inhibitors
}

Shaoping Wu, Lili Yang, Wenji Sun, Longlong Si, Sulong Xiao, Qi Wang, Luc Dechoux, Serge Thorimbert, Matthieu Sollogoub, Demin Zhou, et al.

\section{To cite this version:}

Shaoping Wu, Lili Yang, Wenji Sun, Longlong Si, Sulong Xiao, et al.. Design, synthesis and biological evaluation of gentiopicroside derivatives as potential antiviral inhibitors. European Journal of Medicinal Chemistry, 2017, 130, pp.308-319. 10.1016/j.ejmech.2017.02.028 . hal-01475948

\section{HAL Id: hal-01475948 \\ https://hal.sorbonne-universite.fr/hal-01475948}

Submitted on 24 Feb 2017

HAL is a multi-disciplinary open access archive for the deposit and dissemination of scientific research documents, whether they are published or not. The documents may come from teaching and research institutions in France or abroad, or from public or private research centers.
L'archive ouverte pluridisciplinaire HAL, est destinée au dépôt et à la diffusion de documents scientifiques de niveau recherche, publiés ou non, émanant des établissements d'enseignement et de recherche français ou étrangers, des laboratoires publics ou privés. 


\title{
Design, synthesis and biological evaluation of gentiopicroside derivatives as potential antiviral inhibitors
}

Shaoping Wu ${ }^{\mathrm{a}, \mathrm{b}}$, Lili Yang ${ }^{\mathrm{a}}$, Wenji Sun ${ }^{\mathrm{a}}$, Longlong $\mathrm{Si}^{\mathrm{d}}$, Sulong Xiao ${ }^{\mathrm{d}}$, Qi Wang ${ }^{\mathrm{d}}$, Luc Dechoux ${ }^{\mathrm{b}}$, Serge Thorimbert $^{\mathrm{b}}$, Matthieu Sollogoub ${ }^{\mathrm{b}}$, Demin Zhou ${ }^{\mathrm{d}}$, Yongmin Zhang ${ }^{\mathrm{a}, \mathrm{b}, \mathrm{c}, *}$

\footnotetext{
${ }^{a}$ Key Laboratory of Resource Biology and Biotechnology in Western China (Northwest University), Ministry of Education; Biomedicine Key Laboratory of Shaanxi Province, Northwest University, Xi'an 710069, China

${ }^{b}$ Sorbonne Universités, UPMC Univ Paris 06, Institut Parisien de Chimie Moléculaire, CNRS UMR 8232, 4 place Jussieu, 75005 Paris, France

${ }^{c}$ Institute for Interdisciplinary Research, Jianghan University, Wuhan Economic and Technological Development Zone, Wuhan 430056, China

${ }^{d}$ State Key Laboratory of Natural and Biomimetic Drugs, School of Pharmaceutical Sciences, Peking University, Beijing 100191, China
}

*Address correspondence to this author at the Sorbonne Universités, UPMC Univ Paris 06, CNRS UMR 8232, 4 place Jussieu, 75005 Paris, France. Tel: 33-1-44276153. Fax: 33-1-44275504. E-mails: yongmin.zhang@upmc.fr

\begin{abstract}
Based on classical drug design theory, a novel series of gentiopicroside derivatives was designed and synthesized. All synthesized compounds were then biologically evaluated for their inhibition of influenza virus and anti-HCV activity in vitro. Some of the gentiopicroside derivatives, such as 11a, 13d and $\mathbf{1 6}$ showed interesting anti-influenza virus activity with $\mathrm{IC}_{50}$ at $39.5 \mu \mathrm{M}, 45.2 \mu \mathrm{M}$ and $44.0 \mu \mathrm{M}$, respectively. However, no significant anti-HCV activity was found for all of gentiopicroside derivatives. The preliminary results indicate that modification of the sugar moiety on gentiopicroside was helpful for enhancing the anti-influenza activities. Our works demonstrate the importance of secoiridoid natural products as new leads in the development of potential antiviral inhibitors.
\end{abstract}

Keywords: Natural product, Secoiridoid, Gentiopicroside derivatives, Antiviral agents, Anti-influenza virus.

\section{Introduction}

Viral infections pose a threat to virtually every organism in every domain of life. Some are of great public health importance worldwide, such as influenza virus and Hepatitis $\mathrm{C}$ virus (HCV). Influenza virus is a major human pathogen that can cause annual epidemics and occasional pandemics. It was estimated that influenza epidemics cause 250000 to 500000 deaths every year worldwide [1]. Currently, two classes of anti-influenza drugs, M2 ion channel inhibitors and neuraminidase 
inhibitors, are approved by the FDA for the treatment of influenza virus infection. However, resistance to individual antiviral drugs is probably to appear [2]. On the other hand, $\mathrm{HCV}$ is a major cause of chronic liver diseases which can lead to permanent liver damage, hepatocellular carcinoma and death [3]. The World Health Organization estimates that 130-170 million individuals have detectable antibodies to HCV worldwide, corresponding to $3 \%$ of the world's population. Prior to 2011 , HCV infections were treated with a combination of pegylated interferon A and ribavirin [4]. In 2011 the protease inhibitors boceprevir and telaprevir became available to treat $\mathrm{HCV}$ infection with genotype 1 in combination with ribavirin and pegylated interferon [5, 6]. However, the SVR (Sustained Virologic Response) with current treatment is not optimal, and significant side effects (depression, fatigue, irritability, worsening of mania, insomnia) exist for these drugs. Therefore, there is still a grand challenge for the development of new antiviral inhibitors with unique scaffolds for higher efficacy and improved tolerability.

Natural products play a crucial role in the development of drugs for the treatment of human diseases [7], and to this very day numerous marketed drugs are of natural origin, either as original compounds or after modification [8]. It was found that $10 \%$ of the drugs on the market are unaltered natural products, $29 \%$ are their derivatives (semi-synthetics) and the rest (61\%) have a synthetic origin [9]. The modification of natural products in an effort to alter their biochemical capacity is a common technique utilized by synthetic and medicinal chemists. Moreover, the structural modification of biologically active natural products aims at increasing potency and selectivity, improving physico-chemical, biochemical and pharmacokinetic properties, and eliminating or reducing side effects. More recently, the analogues of natural products are increasingly reported as antiviral inhibitors [10].

Gentiopicroside (GPS), a secoiridoid compound isolated from Gentiana lutea which is called Qin Jiao in Chinese (Fig.1), is one of the most common herbal medicines used in China. Animal experiments have revealed choleretic, anti-hepatotoxic, adaptogenic, and anti-inflammatory activities [11]. It has been investigated for its possible effects on the central nervous system, such as 
antidepressant, anticonvulsant, and analgesic activities in mice [12]. Recently, Khuraman Mustafayeva et al. evaluated the possible genotoxic, mutagenic, and clastogenic effects of gentiopicroside [13]. Very recently, L. Yang et al. reported the hepatoprotective effect of gentiopicroside on anit-induced cholestatic liver injury in mice [14]. However, the main drawback of the gentiopicroside currently being evaluated in clinical trials is its relatively poor lipophilicity and suboptimal pharmacokinetic properties.
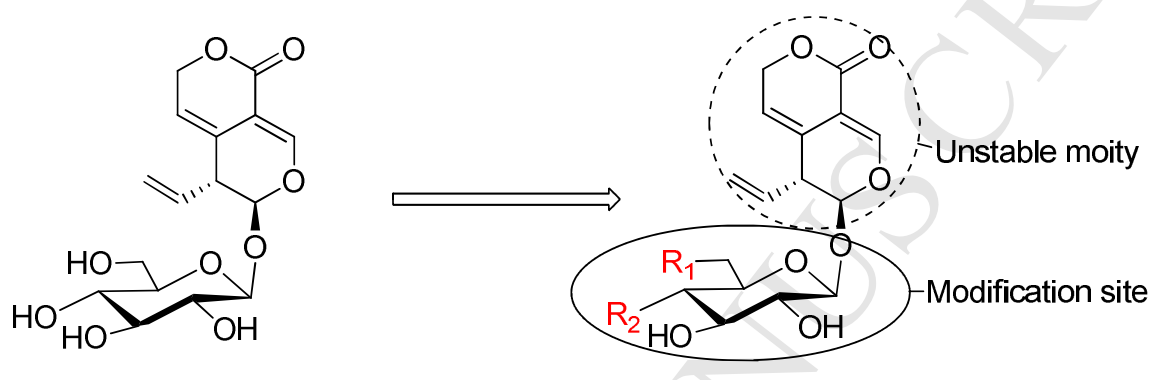

Fig. 1. Structure of gentiopicroside and the designed derivatives.

As part of our ongoing program in the study of gentiopicroside $[15,16]$, in the current work, we describe the design, synthesis and pharmacological evaluation of a series of gentiopicroside derivatives as potential antiviral inhibitors.

\section{Results and discussion}

\subsection{Chemistry}

Structurally, gentiopicroside possesses a complex skeleton featuring fused dipyran glycoside. The compact structure of $\mathbf{1}$ containing two stereocenters, conjugation system and hemiketal, is further exacerbated by its extreme acid and base sensitivity. So we need a mild and efficient protocol for the regioselective preparation of gentiopicroside derivatives. The expeditious and straightforward synthetic route is depicted in Scheme 1. Our synthetic studies commenced with the gentiopicroside that was isolated from the Gentiana lutea. Regioselective protection of the primary hydroxyl group was accomplished by the reaction of $\mathbf{1}$ with triphenylmethyl chloride. Subsequent acetylation of the remaining hydroxyl groups with acetic anhydride gave 
the triacetyl derivative 3. Detriphenylmethylation by treatment with $\mathrm{FeCl}_{3}$ produced the desired intermediates with a free hydroxyl group at primary position [17]. With the alcohol 4 in hands, some common atom or functional group in drug design, such as halogen [18], sulfur [19], and amino group [20] and so on, could be introduced at primary position. The alcohol $\mathbf{4}$ was smoothly converted to the corresponding iodide 5f and bromide 5e in good yield using $\mathrm{Br}_{2} / \mathrm{Ph}_{3} \mathrm{P}$ [21] and $\mathrm{I}_{2} / \mathrm{Ph}_{3} \mathrm{P}$ [22] system. Furthermore, the introduction of a triflate at C-6' in alcohol 4 afforded a unstable intermediate which was followed by displacement with thioacetate [ 23 ], thiomethoxide, azide [24], fluor [25] to yield the desired compounds 5a-5d in good yield at two steps. In addition, the azide compound $\mathbf{5 c}$ was reduced into amino compound by Staudinger reaction [26] as shown in scheme 2. Unfortunately, two compounds, which could not be separated by silica gel chromatography, were obtained on account of acetyl migration [27]. After acetylation, one pure compound 7 was obtained in excellent yield. Final deacetylation could afford the target compound 8. However, attempt to deprotection of the acetyl groups of $\mathbf{5}$ using various reagents such as (i) $\mathrm{NaOMe} / \mathrm{MeOH}$ [28], (ii) $\mathrm{K}_{2} \mathrm{CO}_{3} / \mathrm{MeOH}$ [29], (iii) $\mathrm{Et}_{3} \mathrm{~N} / \mathrm{MeOH} / \mathrm{H}_{2} \mathrm{O}$ [30], (iv) $\mathrm{NH}_{4} \mathrm{OH} / \mathrm{MeOH}$ [31] failed to give the desired compounds; all of compounds underwent decomposition or no reaction under such conditions. Nevertheless, the deprotections were achieved via treating the compounds in methanol with dibutyltin oxide [32] under reflux condition, furnishing the target compounds $\mathbf{6 a - 6 f}$ in excellent yield.

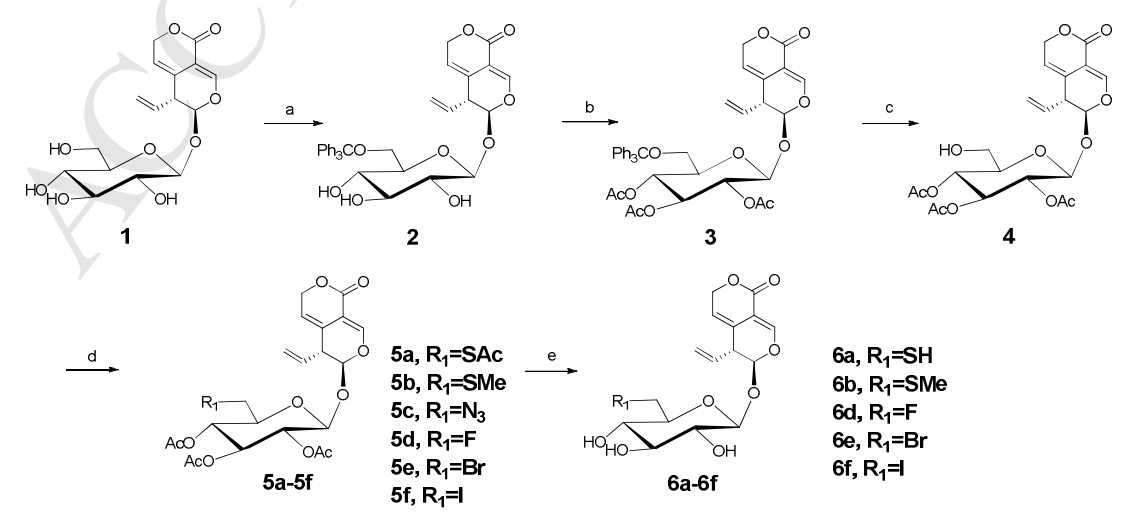

\footnotetext{
Scheme 1. Reagents and conditions: (a) $\mathrm{Ph}_{3} \mathrm{CCl}$, pyridine, $80^{\circ} \mathrm{C}, 3 \mathrm{~h}, 85 \%$; (b) $\mathrm{Ac} 2 \mathrm{O}$, DMAP, pyridine, RT, overnight, 90\%; (c) FeCl ${ }_{3}, \mathrm{DCM}, \mathrm{RT}, 1 \mathrm{~h}, 82 \%$; (d) i) $\mathrm{Tf}_{2} \mathrm{O}$, pyridine, DCM, $0^{\circ} \mathrm{C}, 15 \mathrm{~min}$, then $\mathrm{KSAC}$, DMF, $\mathrm{RT}, 2 \mathrm{~h}, 91 \%$; ii) $\mathrm{Tf}_{2} \mathrm{O}$, pyridine, DCM, $0^{\circ} \mathrm{C}, 15 \mathrm{~min}$, then NaSMe, DMF, RT, $3 \mathrm{~h}, 40 \%$; iii) $\mathrm{Tf}_{2} \mathrm{O}$, pyridine, $\mathrm{DCM}$, $0^{\circ} \mathrm{C}, 15 \mathrm{~min}$, then $\mathrm{NaN}_{3}, \mathrm{DMF}, \mathrm{RT}, 2 \mathrm{~h}, 89 \%$; iv) $\mathrm{Tf}_{2} \mathrm{O}$, pyridine, DCM, $0^{\circ} \mathrm{C}, 15 \mathrm{~min}$, then TBAF, THF, $0{ }^{\circ} \mathrm{C}, 1 \mathrm{~h}, 69 \%$; v) Imazole, $\mathrm{Ph}_{3} \mathrm{P}, \mathrm{I}_{2}, \mathrm{Toluene}^{\circ}, 70^{\circ} \mathrm{C}, 30 \mathrm{~min}$, $53 \%$; vi) $\mathrm{Ph}_{3} \mathrm{P}, \mathrm{Br}_{2}$, pyridine, $0{ }^{\circ} \mathrm{C}$, overnight, $62 \%$; (e) $\mathrm{Bu} \mathrm{S}_{2} \mathrm{SnO}, \mathrm{MeOH}$, reflux, $12 \mathrm{~h}, 74 \%$ for $6 \mathrm{a}, 60 \%$ for $6 \mathrm{~b}, 62 \%$ for $6 \mathrm{~d}, 67 \%$ for $6 \mathrm{e}, 51 \%$ for $6 f$.
} 


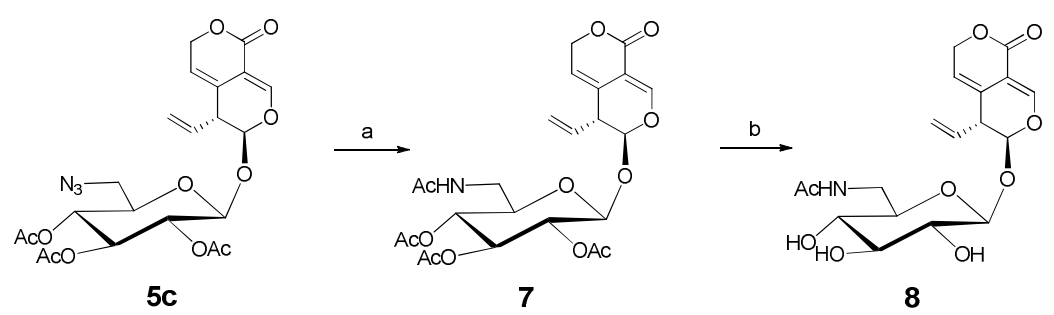

Scheme 2. Reagents and conditions: (a) i) $\mathrm{Ph}_{3} \mathrm{P}, \mathrm{H}_{2} \mathrm{O}, \mathrm{THF}, 50^{\circ} \mathrm{C}, 24 \mathrm{~h}$; ii) $\mathrm{Ac} \mathrm{C}_{2} \mathrm{O}$, DMAP, pyridine, RT, overnight, $90 \%$ in two steps; (b) $\mathrm{Bu}_{2} \mathrm{SnO}, \mathrm{MeOH}$, reflux, $12 \mathrm{~h}, 46 \%$.

On the other hand, the sugar moiety of gentiopicroside was selectively and quantitatively converted into the corresponding 6'-TIPS derivative 9 by treatment with TIPSCl in DMF at room temperature for overnight in the presence of imidazole. Subsequent benzoylation reaction generated the compound $\mathbf{1 0}$ in high yields. Treatment of 10 with TBAF cleaved the TIPS protecting group to give rise an intramolecular migration of the benzoyl group at C-4' to the less crowded C-6' position [33]. The structures of $\mathbf{1 1}$ was confirmed by its conversion into the corresponding mesyl derivatives 11a as its ${ }^{1} \mathrm{H}$ NMR for H-4' of the glucose moiety displayed deshielded signals at $\delta 5.18\left(\mathrm{dd}, J_{4,5}=12.2 \mathrm{~Hz}, J_{3,4}=9.7 \mathrm{~Hz}\right)$, indicating the position of the formed free hydroxyl in the derivative $\mathbf{1 1}$ to be at 4' position in sugar moiety. The alcohol 11 was then converted into the corresponding triflate derivative, followed by nucleophilic substitution with $\mathrm{KNO}_{2}, \mathrm{KSAc}, \mathrm{NaN}_{3}$, and TBAF to provide the derivatives 12a-12d in excellent yields. Finally the desired compounds were obtained in moderate yields after debenzoylation under the aforementioned conditions. At the same time, the alcohol 12a was converted into the corresponding equatorial $\mathbf{S H}$, $\mathrm{N}_{3}, \mathrm{~F}$ substituents by the same two-step process. The final deprotection of $\mathbf{1 2 b - 1 2 d}$ using dibutyltin oxide proceeded successfully to afford the target molecules 13b-13d in moderate yields (Scheme 3.). It is worth to note that the C-4' triflate was reacted with TBAF starting from the suitably protected 12a to unsuccessfully give the desired 4'-fluoro compound $\mathbf{1 4 c}$, the elimination product $\mathbf{1 6}$ (see supporting information) was observed as described in the literature [34]. DAST reagent was used to introduce an equatorial fluorine at C-4' of sugar moiety in gentiopicroside. Final deprotection of 14a-14c by using dibutyltin oxide proceeded to afford the target molecules 15a-15c in moderate yields (Scheme 4.). Unfortunately, 15b and 15c were obtained as mixture of 
compounds.

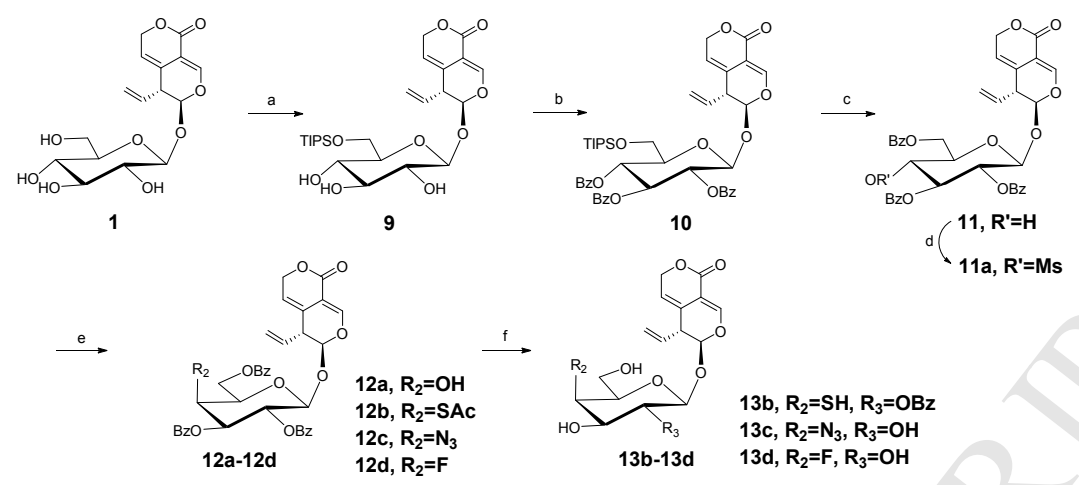

Scheme 3. Reagents and conditions: (a) TIPSCI, Imazole, DMAP, DMF, RT, overnight, $91 \%$; (b) BzCl, DMAP, pyridine, RT, overnight, $85 \%$; (c) TBAF, THF, $0{ }^{\circ} \mathrm{C}, 1 \mathrm{~h}, 78 \%$; (d) MsCl, $\mathrm{Et}{ }_{3} \mathrm{~N}, \mathrm{DCM}, 0{ }^{\circ} \mathrm{C}, 1 \mathrm{~h}$; 92\%; (e) i) $\mathrm{Tf}_{2} \mathrm{O}$, pyridine, $\mathrm{DCM}, 0{ }^{\circ} \mathrm{C}, 15 \mathrm{~min}$, then $\mathrm{KNO}_{2}, \mathrm{DMF}^{\circ} 50{ }^{\circ} \mathrm{C}, 2 \mathrm{~h}$, $85 \%$; ii) $\mathrm{Tf}_{2} \mathrm{O}$, pyridine, $\mathrm{DCM}, 0{ }^{\circ} \mathrm{C}, 15 \mathrm{~min}$, then KSAC, DMF, RT, $2 \mathrm{~h}, 93 \%$; iii) $\mathrm{Tf}_{2} \mathrm{O}$, pyridine, $\mathrm{DCM}, 0{ }^{\circ} \mathrm{C}, 15 \mathrm{~min}$, then $\mathrm{NaN}_{3}, \mathrm{DMF}, \mathrm{RT}, 2 \mathrm{~h}$, $91 \%$; iv) $\mathrm{Tf}_{2} \mathrm{O}$, pyridine, $\mathrm{DCM}, 0^{\circ} \mathrm{C}, 15 \mathrm{~min}$, then TBAF, $\mathrm{THF}, \mathrm{O}^{\circ} \mathrm{C}, 1 \mathrm{~h}, 51 \%$. (f) $\mathrm{Bu} 2 \mathrm{SnO}, \mathrm{MeOH}$, reflux, $20 \mathrm{~h}, 65 \%$ for $13 \mathrm{~b}, 40 \%$ for $13 \mathrm{c}, 42 \%$ for $13 \mathrm{~d}$.

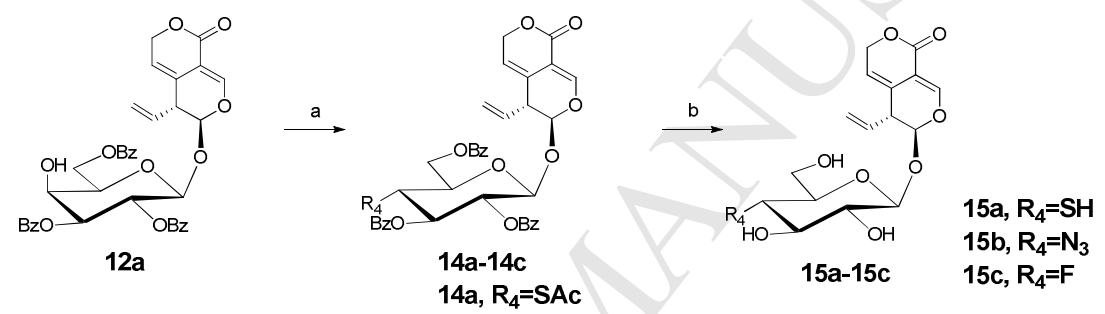

Scheme 4. Reagents and conditions: (a) i) $\mathrm{Tf}_{2} \mathrm{O}$, pyridine, $\mathrm{DCM}, 0^{\circ} \mathrm{C}, 15 \mathrm{~min}$, then $\mathrm{KSAc}, \mathrm{DMF}, \mathrm{RT}, 2 \mathrm{~h}, 76 \%$; ii) $\mathrm{Tf}_{2} \mathrm{O}$, pyridine, $\mathrm{DCM}, \mathrm{O}^{\circ} \mathrm{C}, 15 \mathrm{~min}$, then $\mathrm{NaN}_{3}, \mathrm{DMF}, \mathrm{RT}, 1 \mathrm{~h}, 78 \%$; iii) DAST, pyridine, $\mathrm{DCM},-25{ }^{\circ} \mathrm{C}, 3 \mathrm{~h}, 80 \%$. (b) $\mathrm{Bu}_{2} \mathrm{SnO}, \mathrm{MeOH}$, reflux, $12 \mathrm{~h}, 47 \%$ for $15 \mathrm{a}, 31 \%$ for $15 b, 46 \%$ for $15 \mathrm{c}$.

The synthesized compounds were fully characterized by physicochemical and spectral means. The MS and ${ }^{1} \mathrm{H}$ NMR, ${ }^{13} \mathrm{C}$ NMR spectral data were found in agreement with the assigned molecular structures.

\subsection{Biological evaluations}

\subsubsection{Inhibition of influenza virus infectivity}

To explore the novel gentiopicroside derivatives as anti-influenza agents, we first determined their cytotoxicity in MDCK cells by the CellTiter-Glo ${ }^{\circledR}$ assay. As shown in Fig 2A, except compound 2, all the other derivatives of gentiopicorside showed no cytotoxicity to uninfected MDCK cells at concentration of $50 \mu \mathrm{M}$. Compound 2 exhibited strong cell toxicity at the same concentration indicating that the triphenylmethyl group could be a toxic group, which agreed well with previous work by Sirion et al. They first reported that the introduction of triphenylmethyl ester group into C-19 of andrographolide led to increase in toxicity against a series of cancer cell 
lines [35].

Except compound 2, gentiopicroside and some of its derivatives were selected for evaluation against the influenza A/WSN/33 (H1N1) virus that was propagated in MDCK cells by the cytopathic effect (CPE) reduction assay. Oseltamivir (OSV), an inhibitor of influenza neuraminidase, was used as a positive control. The screening results are shown in Fig. 2B. We found that: 1) compounds 11a, 13d, and 16 significantly reduced the viral CPE, but the other compounds had less activity; 2) the hydrophobicity of gentiopicroside may be helpful for the binding with its target since two gentiopicroside derivatives 11a and $\mathbf{1 6}$ are two multi-benzoyl substituted gentiopicroside derivatives with good anti-influenza activity; 3) 4'-substituted group has important effect on the anti-influenza activity. Chang of the conformation of 4'-fluoro from 4'-axial (13d) to 4'-equatorial (15c) or shift of the fluoro substituent from 4'-axial (13d) to the adjacent 6' (6d) significantly decreased or even eliminated the activity.
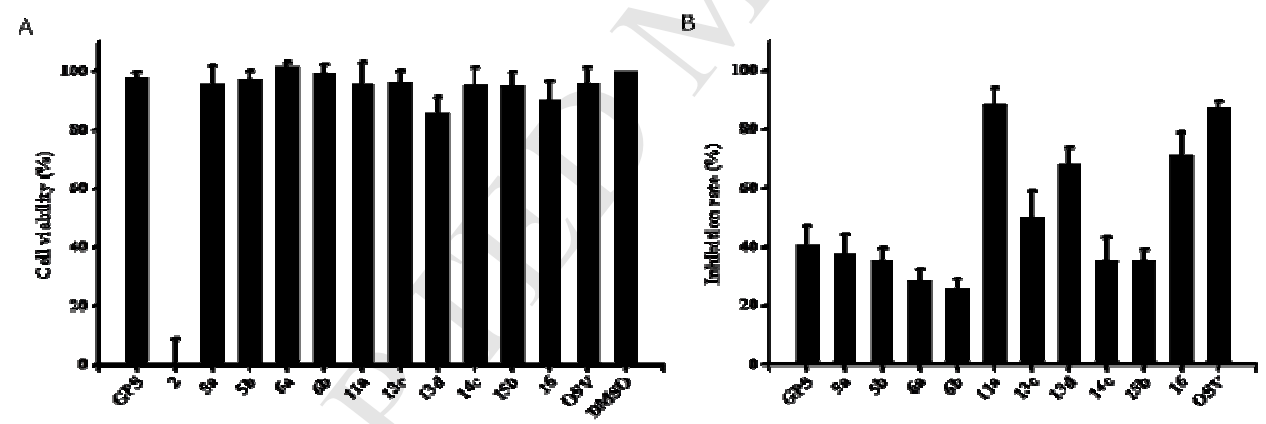

Fig. 2. Inhibitory effects of gentiopicorside derivatives $(50 \mu \mathrm{M})$ against anti-influenza virus. (A) The cytotoxic effects of gentiopicorside derivatives $(50 \mu \mathrm{M})$ using CellTiter-Glo ${ }^{\circledR}$ Assay. DMSO was used as a negative control. (B) The anti-influenza virus activity of gentiopicorside derivatives $(50 \mu \mathrm{M})$ and positive control, respectively. Error bars indicate standard deviations of triplicate experiments.

Three compounds 11a, 13d and $\mathbf{1 6}$ as well as OSV identified with high inhibition rates in the initial screening were selected for the dose response assays. The concentrations required to inhibit viral replication by $50 \%\left(\mathrm{IC}_{50}\right)$ are summarized in Table 1. Though compounds $\mathbf{1 3 d}$ and $\mathbf{1 6}$ showed a little weaker activity than OSV $\left(\mathrm{IC}_{50}: 45.2 \pm 2.9 \mu \mathrm{M}\right.$ vs $\left.44.0 \pm 4.1 \mu \mathrm{M}\right)$, they can be used as a new lead compound of anti-influenza inhibitor for further structure modification. 
Table 1. In vitro anti-influenza virus activity of the lead compounds

\begin{tabular}{cc}
\hline Compound & $\mathrm{IC}_{50}(\mu \mathrm{M})$ \\
\hline 11a & $39.5 \pm 3.2$ \\
13d & $45.2 \pm 2.9$ \\
$\mathbf{1 6}$ & $44.0 \pm 4.1$ \\
OSV & $33.6 \pm 2.2$ \\
\hline
\end{tabular}

The anti-influenza activity of 11a, the most representative compound in this study, was further confirmed by direct microscopic observation. Far less CPE was observed when treated with 11a at $50 \mu \mathrm{M}$ than DMSO (Fig. 3).

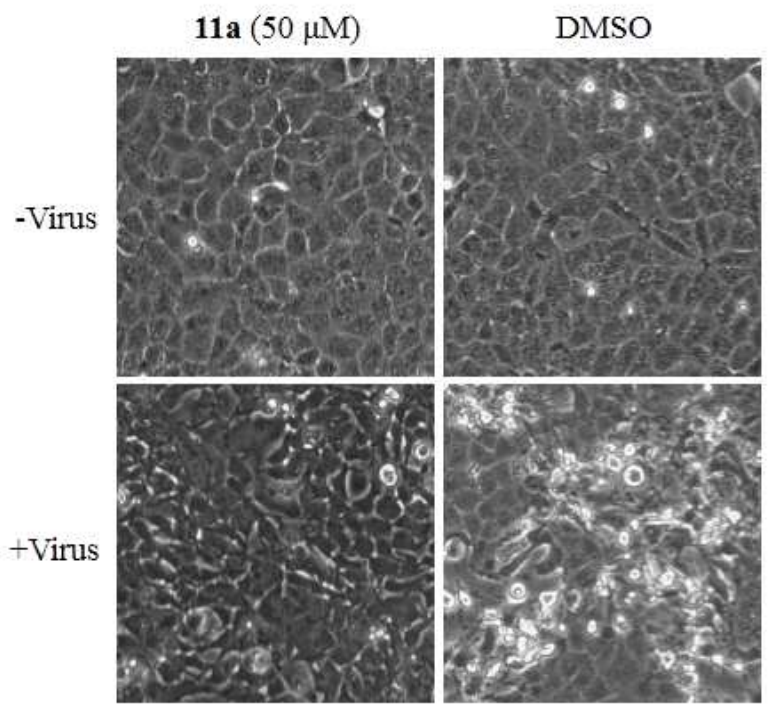

Fig. 3. Direct microscopic observation of the CPE inhibition by compound 11a.

\subsubsection{Inhibition of HCV infectivity}

Concerning the fact that gentiopicroside has the hepatoprotective effect on anit-induced cholestatic liver injury in mice [14], the synthesized compounds (2 16) were first evaluated for their anti-HCVpp entry activity by using a previous method [36]. Two concentrations, $1 \mu \mathrm{M}$ and $5 \mu \mathrm{M}$, were tested for each compound. DMSO is a negative control for monitoring the maximum HCVpp entry in the presence of $1 \%$ DMSO. Echinocystic acid (EA) is a positive control to reflect the blocking of HCVpp entry. As compared to their parent compound gentiopicroside, compound 11a showed better anti-HCVpp entry activity at the concentrations of $1 \mu \mathrm{M}$ and $5 \mu \mathrm{M}$, three other compounds 14a, 15c and 16 also showed better inhibition in a significant 
dose-dependence manner in the primary assay. However, they all showed much weaker inhibition of HCVpp infection than the positive control (see Table S1.). Those results indicated that gentiopicorside is not a good lead compound for HCV entry.

\section{Conclusion}

In summary, a novel type of gentiopicroside derivatives have been designed and synthesized efficiently, and their antiviral activities against influenza virus and HCV were evaluated in vitro. No significant anti-HCV activity was found for those new gentiopicroside derivatives. However, some of the gentiopicroside derivatives, such as 11a, 13d and 16, exhibited potent anti-influenza activities with $\mathrm{IC}_{50}$ at $39.5 \mu \mathrm{M}, 45.2$ $\mu \mathrm{M}$ and $44.0 \mu \mathrm{M}$, respectively. The preliminary results indicate that modification of the sugar moiety on gentiopicroside is essential for enhancing biological activities.

Further optimization of new gentiopicroside derivatives based on the lead compound 13d aiming at improving inhibition activities against anti-influenza virus is currently ongoing in our groups and will be reported in due course.

\section{Experimental section}

\subsection{Chemistry-general}

All reactions were performed under nitrogen atmosphere. Reagents were all analytically or chemically pure and used without further purification unless specified. Solvents were reagent grade and, when necessary, were purified and dried by standard methods. ${ }^{1} \mathrm{H}$ NMR and ${ }^{13} \mathrm{C}$ NMR spectra were recorded on a Bruker 400 spectrometer using $\mathrm{CDCl}_{3}$ as solvent and tetramethylsilane as internal standard. Chemical shifts are reported in parts per million $(\delta)$, and signals are expressed as s (singlet), $\mathrm{d}$ (doublet), $\mathrm{t}$ (triplet), q (quartet) or m (multiplet). High resolution mass spectral (HRMS) analyses were taken on a Bruker micrOTOF mass spectrometer using electron spray ionization. Optical rotations were determined with a JASCO P-2000 polarimeter. TLC was performed on Silica Gel GF254 for TLC (Merck) and spots were visualized by CAM containing Cerium Sulfate (1.0 g) and ammonium molybdate (VI) tetrahydrate (25.0 g) in $10 \% \mathrm{H}_{2} \mathrm{SO}_{4}(500 \mathrm{~mL})$ followed by heating or by irradiation with UV light (254 nm). 
Flash column chromatography was performed on column packed with Silica Gel 60 (200-300 mesh, Merck).

4.2. Synthesis

\subsubsection{6'-O-Triphenylmethyl gentiopicroside (2)}

A solution of gentiopicroside (502 mg, $1.41 \mathrm{mmol}, 1.0$ equiv.) and $\operatorname{TrCl}(708 \mathrm{mg}$, $2.54 \mathrm{mmol}, 1.8$ equiv.) in pyridine $(5 \mathrm{~mL})$ was stirred an $80{ }^{\circ} \mathrm{C}$ for $3 \mathrm{~h}$. The mixture was concentrated in vacuum and co-concentrated with toluene $(5 \mathrm{~mL})$. The residue was dissolved in $\mathrm{CH}_{2} \mathrm{Cl}_{2}(2 \times 20 \mathrm{~mL})$, washed with water saturated sodium hydrogen carbonate solution $(20 \mathrm{~mL})$ and brine $(20 \mathrm{~mL})$. The organic phase was dried by anhydrous magnesium sulfate, filtered and concentrated. The residue was purified by flash column chromatography (Ethyl Acetate/methanol/Cyclohexane, 5:1:2) to give compound $2(718.8 \mathrm{mg}, 85 \%)$ as a yellow foam. $\mathrm{R}_{\mathrm{f}}=0.35$ (Ethyl Acetate/methanol, 5:1). $[\alpha]_{D}^{20}=-90.2\left(\mathrm{c} 1.0, \mathrm{CHCl}_{3}\right) .{ }^{1} \mathrm{H} \mathrm{NMR}\left(400 \mathrm{MHz}\right.$, Acetone- $\left.d_{6}\right): \delta 7.38(\mathrm{dd}, J=$ 8.5, 2.0 Hz, 5H, H arom), 7.28 (d, J=1.2 Hz, 1H, H-3), 7.25-7.03 (m, 10H, H arom), 5.79-5.60 (m, 1H, H-8), 5.55 (d, $J=3.2 \mathrm{~Hz}, 2 \mathrm{H}, \mathrm{H}-1, \mathrm{H}-6), 5.24-5.04$ (m, 2H, H-10a, H-10b), 5.01-4.77 (m, 2H, H-7a, H-7b), 4.64 (d, J = 7.8 Hz, 1H, H-1'), 3.52-3.39 (m, 1H, H-5'), 3.39-3.23 (m, 4H, H-3', H-4', H-9, H-6'a), 3.24-3.06 (m, 2H, H-6'b, H-2'). ${ }^{13} \mathrm{C}$ NMR (101 MHz, Acetone- $\left.d_{6}\right): \delta 163.36$ (C-11), 149.39 (C-3), 145.27 (C arom quat), 135.01 (C-8), 129.61, 128.58, 127.82 (C arom tert), 126.76 (C-5), 118.51 (C-10), 117.13 (C-6), 104.90 (C-4), 100.39 (C-1'), 98.29 (C-1), $87.02\left(\underline{C P h}_{3}\right), 78.09$ (C-5'), 76.73 (C-3'), 74.33 (C-2'), 71.42 (C-4'), 69.93 (C-7), 64.41 (C-6’),46.43 (C-9). HRMS (ESI): $m / z$ Calcd. for $\mathrm{C}_{35} \mathrm{H}_{34} \mathrm{O}_{9} \mathrm{Na}[\mathrm{M}+\mathrm{Na}]^{+}$621.2095, found 621.2141 (-4.6 ppm).

\subsubsection{2',3',4'-Tri-O-acetyl-6'-O-Triphenylmethyl gentiopicroside (3)}

Acetic anhydride $(0.6 \mathrm{~mL}, 6.0 \mathrm{mmol}, 5.0$ equiv.) was added to a solution of 2 (718.2 mg, $1.2 \mathrm{mmol}, 1.0$ equiv.), DMAP (14.6 mg, $0.12 \mathrm{mmol}, 0.1$ equiv.) in anhydrous pyridine $(20 \mathrm{~mL})$ and then stirred at room temperature under nitrogen for 8 h. The solution was evaporated in vacuum, then dissolved in $\mathrm{CH}_{2} \mathrm{Cl}_{2}(30 \mathrm{~mL})$, washed with water $(20 \mathrm{~mL})$, saturated sodium hydrogen carbonate solution $(20 \mathrm{~mL})$ and brine $(20 \mathrm{~mL})$. The organic phase was dried anhydrous magnesium sulfate, filtered and 
concentrated. The residue was purified by flash column chromatography (Ethyl Acetate/Cyclohexane, 1:3) to give compound 3 (779.5 mg, 90\%) as a yellow foam. $R_{f}$ $=0.33\left(\right.$ Ethyl Acetate/Cyclohexane, 2:3). $[\alpha]_{D}^{20}=-65.1\left(\mathrm{c} 1.0, \mathrm{CHCl}_{3}\right) \cdot{ }^{1} \mathrm{H}$ NMR $(400$ $\mathrm{MHz}, \mathrm{CDCl}_{3}$ ): $\delta$ 7.41-7.17 (m, 16H, $15 \times \mathrm{H}$ arom, H-3), 5.67 (ddd, $J=17.3,10.2,7.2$ $\mathrm{Hz}, 1 \mathrm{H}, \mathrm{H}-8$ ), 5.57 (ddt, $J=4.4,2.5,1.1 \mathrm{~Hz}, 1 \mathrm{H}, \mathrm{H}-6), 5.47$ (d, $J=2.6 \mathrm{~Hz}, 1 \mathrm{H}, \mathrm{H}-1$ ), 5.25 (dt, $J=9.1,1.2 \mathrm{~Hz}, 1 \mathrm{H}, \mathrm{H}-10 \mathrm{a}), 5.23-5.20$ (m, 1H, H-10b), 5.20-5.16 (m, 1H, H-4'), 5.15-5.07 (m, 1H, H-3'), 5.06-4.89 (m, 3H, H-7a, H-7b, H-2'), 4.83 (d, J = 8.0 Hz, 1H, H-1'), 3.56 (ddd, $J=9.5,4.4,2.4$ Hz, 1H, H-5'), 3.38-3.25 (m, 2H, H-9, H-6'a), 3.07 (dd, $J=10.7,4.4 \mathrm{~Hz}, 1 \mathrm{H}, \mathrm{H}-6$ 'b), 1.95 (s, 3H, $\underline{\mathrm{H}}_{3} \mathrm{CO}$ ), 1.93 (s, 3H, $\left.\mathrm{C}_{3} \mathrm{CO}\right), 1.72$ (s, 3H, $\left.\underline{\mathrm{H}}_{3} \mathrm{CO}\right) .{ }^{13} \mathrm{C} \mathrm{NMR}\left(101 \mathrm{MHz}, \mathrm{CDCl}_{3}\right): \delta 170.26\left(\mathrm{CH}_{3} \underline{\mathrm{CO}}\right)$, $169.24\left(\mathrm{CH}_{3} \underline{\mathrm{CO}}\right), 169.00\left(\mathrm{CH}_{3} \underline{\mathrm{CO}}\right), 163.26$ (C-11), 148.14 (C-3), 143.60 (C arom), 132.90 (C-8), 128.76-127.20 (C arom), 125.44 (C-5), 118.85 (C-10), 116.75 (C-6), 104.35 (C-4), 96.72 (C-1), 96.38 (C-1'), $86.75\left(\underline{\mathrm{CPh}}_{3}\right), 73.73$ (C-5'), 72.75 (C-3’), 70.83 (C-2’), 69.46 (C-7), 68.58 (C-4'), 61.85 (C-6'), 45.39 (C-9), 20.69 ( $\left.\underline{\mathrm{CH}}_{3} \mathrm{CO}\right)$, $20.59\left(\underline{\mathrm{CH}}_{3} \mathrm{CO}\right), 20.48\left(\underline{\mathrm{CH}}_{3} \mathrm{CO}\right) . \mathrm{HRMS}(\mathrm{ESI}): \mathrm{m} / z$ Calcd. for $\mathrm{C}_{41} \mathrm{H}_{40} \mathrm{O}_{12} \mathrm{Na}[\mathrm{M}+\mathrm{Na}]^{+}$ 747.2413, found $747.2412(-0.1 \mathrm{ppm})$.

\subsubsection{2',3',4'-Tri-O-acetyl gentiopicroside (4)}

To a solution of tritylated 3 (42 mg, $0.058 \mathrm{mmol}, 1.0$ equiv.) in $\mathrm{CH}_{2} \mathrm{Cl}_{2}(3 \mathrm{~mL})$ was added solid $\mathrm{FeCl}_{3}$ (19 mg, $0.12 \mathrm{mmol}, 2.0$ equiv.). The mixture was stirred at room temperature for $40 \mathrm{~min}$, after which time the reaction was complete as indicated by TLC. Water $(5 \mathrm{~mL})$ was added and the mixture was diluted with Ethyl Acetate $(2 \times 5 \mathrm{~mL})$. The organic layers were combined, dried over anhydrous magnesium sulfate, The residue was purified by flash column chromatography (Ethyl Acetate/Cyclohexane, $1: 1)$ to give compound $4(23 \mathrm{mg}, 82 \%)$ as a white foam. $R_{\mathrm{f}}=$

0.29 (Ethyl Acetate/Cyclohexane, 2:1). $[\alpha]_{D}^{20}=-159.6\left(\mathrm{c} 1.0, \mathrm{CHCl}_{3}\right) .{ }^{1} \mathrm{H} \mathrm{NMR}(400$ $\left.\mathrm{MHz}, \mathrm{CDCl}_{3}\right): \delta 7.36(\mathrm{q}, J=1.3 \mathrm{~Hz}, 1 \mathrm{H}, \mathrm{H}-3), 5.62(\mathrm{ddd}, J=17.3,10.3,7.1 \mathrm{~Hz}, 1 \mathrm{H}$, H-8), 5.54 (dd, $J=3.6,2.6 \mathrm{~Hz}, 1 \mathrm{H}, \mathrm{H}-6), 5.44$ (d, $J=2.3 \mathrm{~Hz}, 1 \mathrm{H}, \mathrm{H}-1$ ), 5.28-5.21 (m, 1H, H-3'), 5.21-5.19 (m, 1H, H-10a), 5.19-5.15 (m, 1H, H-10b), 5.10-4.97 (m, 2H, H-7a, H-4'), 4.97-4.90 (m, 1H, H-7b), 4.90-4.84 (m, 2H, H-2', H-1'), 3.83-3.67 (m, 
1H, H-6'a), 3.64-3.48 (m, 2H, H-6'b, H-5'), 3.26 (ddd, $J=6.9,2.5,1.2$ Hz, 1H, H-9), 2.03 (s, 3H, $\left.\underline{\mathrm{H}}_{3} \mathrm{CO}\right), 1.97$ (s, 3H, $\left.\mathrm{C}_{3} \mathrm{CO}\right), 1.91$ (s, 3H, $\left.\underline{\mathrm{H}}_{3} \mathrm{CO}\right) .{ }^{13} \mathrm{C}$ NMR (101 $\left.\mathrm{MHz}, \mathrm{CDCl}_{3}\right): \delta 170.41\left(\mathrm{CH}_{3} \underline{\mathrm{CO}}\right), 170.08\left(\mathrm{CH}_{3} \underline{\mathrm{CO}}\right), 169.13\left(\mathrm{CH}_{3} \underline{\mathrm{CO}}\right), 163.27(\mathrm{C}-11)$, 147.87 (C-3), 132.78 (C-8), 125.20 (C-5), 118.70 (C-10), 116.85 (C-6), 104.36 (C-4), 96.59 (C-1), 96.08 (C-1'), 74.56 (C-5'), 72.22 (C-2'), 70.72 (C-4'), 69.44 (C-7), 68.50 (C-3'), 60.95 (C-6'), 45.11 (C-9), 20.70 ( $\left.\underline{\mathrm{CH}}_{3} \mathrm{CO}\right), 20.64$ ( $\left.\underline{\mathrm{C}} \mathrm{H}_{3} \mathrm{CO}\right), 20.52\left(\underline{\mathrm{CH}}_{3} \mathrm{CO}\right)$. HRMS (ESI): $m / z$ Calcd. for $\mathrm{C}_{22} \mathrm{H}_{26} \mathrm{O}_{12} \mathrm{Na}[\mathrm{M}+\mathrm{Na}]^{+}$505.1316, found 505.1316 (0 ppm).

\subsubsection{2',3',4'-Tri-O-acetyl-6'-(1,1,1-trifluoromethanesulfonyl) gentiopicroside (5)}

Trifluoromethanesulfonic anhydride (41 $\mu \mathrm{L}, 0.24 \mathrm{mmol}, 2.0$ equiv.) was added dropwise at $0{ }^{\circ} \mathrm{C}$ to a stirred solution of 4 (56 mg, $0.12 \mathrm{mmol}, 1.0$ equiv.) in $\mathrm{CH}_{2} \mathrm{Cl}_{2}$ (3 $\mathrm{mL})$. After $2 \mathrm{~min}$, pyridine $(100 \mu \mathrm{L})$ was added to this stirred solution at the same temperature. After $15 \mathrm{~min}$, the reaction mixture was diluted with $\mathrm{CH}_{2} \mathrm{Cl}_{2}(5 \mathrm{~mL})$ and washed successively with $1 \mathrm{M} \mathrm{HCl}(2 \mathrm{~mL})$, saturated aqueous sodium hydrogen carbonate $(5 \mathrm{~mL})$ and water $(5 \mathrm{~mL})$. The separated organic layer was dried over anhydrous magnesium sulfate and concentrated in vacuum at low temperature. The residue was used directly in the next step without further purification. $\mathbf{R}_{\mathbf{f}}=0.38$ (Ethyl Acetate/Cyclohexane, 1:1).

\subsubsection{2',3',4'-Tri-O-acetyl-6'-S-acetyl-6'-thio-6'-deoxy gentiopicroside (5a)}

Potassium thioacetate $(10.0 \mathrm{mg}, 0.082 \mathrm{mmol}, 2.0$ equiv.) was added to a solution of the protected triflate residue $5(25.2 \mathrm{mg}, 0.041 \mathrm{mmol}, 1.0$ equiv.) in anhydrous DMF (2 mL). After stirring at room temperature for $2 \mathrm{~h}$, the mixture was diluted with Ethyl Acetate $(2 \times 5 \mathrm{~mL})$ and washed with brine $(5 \mathrm{~mL})$. The organic phase was dried with anhydrous magnesium sulfate and concentrated in vacuum. Purification of the residue by flash column chromatography (Ethyl Acetate/Cyclohexane, 1:1) afforded the thiolacetate derivative $\mathbf{5 a}\left(22 \mathrm{mg}, 98 \%\right.$ in two steps). $\mathrm{R}_{\mathrm{f}}=0.35$ (Ethyl Acetate/Cyclohexane, 2:1). $[\alpha]_{D}^{20}=-70.4\left(\mathrm{c} 1.0, \mathrm{CHCl}_{3}\right) .{ }^{1} \mathrm{H} \mathrm{NMR}\left(400 \mathrm{MHz}, \mathrm{CDCl}_{3}\right)$ : $\delta$ 7.41-7.32 (m, 1H, H-3), 5.72-5.59 (m, 1H, H-8), 5.54 (dd, $J=3.5,2.8,1.6 \mathrm{~Hz}, 1 \mathrm{H}$, H-6), 5.42-5.34 (m, $J=3.4,1 \mathrm{H}, \mathrm{H}-1), 5.21$ (dd, $J=7.9,1.2 \mathrm{~Hz}, 1 \mathrm{H}, \mathrm{H}-10 \mathrm{a}), 5.18$ (t, $J$ 
$=1.2 \mathrm{~Hz}, 1 \mathrm{H}, \mathrm{H}-10 \mathrm{~b}), 5.14$ (t, $J=9.5 \mathrm{~Hz}, 1 \mathrm{H}, \mathrm{H}-3$ '), 5.05 (ddt, $J=17.7,2.5,1.2 \mathrm{~Hz}$, 1H, H-7a), 4.95 (d, J=3.2 Hz, 1H, H-7b), 4.94-4.90 (m, 1H, H-4'), 4.90-4.84 (m, 1H, H-2'), 4.82-4.74 (m, $J=7.8,1 \mathrm{H}, \mathrm{H}-1$ ') 3.64 (ddd, $J=9.7,6.6,3.0 \mathrm{~Hz}, 1 \mathrm{H}, \mathrm{H}-5$ '), 3.32-3.16 (m, 2H, H-9, H-6'a), 3.06 (dd, J = 14.4, 6.6 Hz, 1H, H-6'b), 2.32 (s, 3H, $\mathrm{SAc}), 2.04$ (d, J=7.2 Hz, 3H, $\left.\underline{\mathrm{H}}_{3} \mathrm{CO}\right), 1.95$ (s, 3H, $\left.\underline{\mathrm{H}}_{3} \mathrm{CO}\right), 1.90$ (d, J = 5.5 Hz, 3H, $\left.\mathrm{C}_{3} \mathrm{CO}\right) .{ }^{13} \mathrm{C} \mathrm{NMR}\left(101 \mathrm{MHz}, \mathrm{CDCl}_{3}\right): \delta 194.41$ (SAc), $170.04\left(\mathrm{CH}_{3} \underline{\mathrm{CO}}\right), 169.76$ $\left(\mathrm{CH}_{3} \underline{\mathrm{CO}}\right), 169.08$ ( $\left.\mathrm{CH}_{3} \underline{\mathrm{CO}}\right), 163.17$ (C-11), 147.90 (C-3), 132.74 (C-8), 125.29 (C-5), 118.78 (C-10), 116.81 (C-6), 104.37 (C-4), 96.64 (C-1), 96.00 (C-1'), 73.47 (C-5'), 72.33 (C-3’), 70.59 (C-4'), 70.36 (C-2'), 69.42 (C-7), 45.13 (C-9), 30.48 ( $\mathrm{SCOCH}_{3}$ ), 29.99 (C-6'), 20.73 ( $\left.\underline{\mathrm{CH}}_{3} \mathrm{CO}\right), 20.60$ ( $\left.\underline{\mathrm{CH}}_{3} \mathrm{CO}\right), 20.51$ ( $\left.\underline{\mathrm{CH}}_{3} \mathrm{CO}\right) . \mathrm{HRMS}(\mathrm{ESI}): \mathrm{m} / \mathrm{z}$ Calcd. for $\mathrm{C}_{24} \mathrm{H}_{28} \mathrm{O}_{11} \mathrm{SNa}[\mathrm{M}+\mathrm{Na}]^{+}$563.1306, found $563.1302(0.7 \mathrm{ppm})$.

\subsubsection{2',3',4'-Tri-O-acetyl-6'-S-methyl-6'-thio-6'-deoxy gentiopicroside (5b)}

Sodium thiomethoxide ( $31.0 \mathrm{mg}, 0.44 \mathrm{mmol}, 1.3$ equiv.) was added to a solution of the protected triflate residue 5 (163 $\mathrm{mg}, 0.43 \mathrm{mmol}, 1.0$ equiv.) in anhydrous DMF $(2 \mathrm{~mL})$. After stirring at room temperature for $2 \mathrm{~h}$, the mixture was diluted with Ethyl Acetate $(2 \times 5 \mathrm{~mL})$ and washed with brine $(5 \mathrm{~mL})$. The organic phase was dried with anhydrous magnesium sulfate and concentrated in vacuum. Purification of the residue by flash column chromatography (Ethyl Acetate/Cyclohexane, 1:1) afforded the thiolacetate derivative $\mathbf{5 b}\left(71.0 \mathrm{mg}, 98 \%\right.$ in two steps). $\mathrm{R}_{\mathrm{f}}=0.42$ (Ethyl Acetate/Cyclohexane, 1:1). $[\alpha]_{D}^{20}=-54.0\left(\mathrm{c} 1.0, \mathrm{CHCl}_{3}\right) .{ }^{1} \mathrm{H} \mathrm{NMR}\left(400 \mathrm{MHz}, \mathrm{CDCl}_{3}\right)$ : $\delta 7.41(\mathrm{~d}, J=1.6 \mathrm{~Hz}, 1 \mathrm{H}, \mathrm{H}-3), 5.65$ (ddd, $J=19.6,10.1,7.2 \mathrm{~Hz}, 1 \mathrm{H}, \mathrm{H}-8), 5.55$ (ddd, $J=5.5,3.7,2.2 \mathrm{~Hz}, 1 \mathrm{H}, \mathrm{H}-6), 5.47-5.38$ (m, 1H, H-1), $5.23(\mathrm{dt}, J=4.9,1.2 \mathrm{~Hz}, 1 \mathrm{H}$, H-10a), 5.22-5.19 (m, 1H, H-10b), 5.18 (d, J = 9.6 Hz, 1H, H-3'), 5.12-5.04 (m, 1H, H-7a), 5.00 (d, J = 9.6 Hz, 1H, H-4'), 4.99-4.94 (m, 1H, H-2'), 4.94-4.90 (m, 1H, H-7b), 4.85 (d, $J=8.1 \mathrm{~Hz}, 1 \mathrm{H}, \mathrm{H}-1$ '), 3.70 (ddd, $J=10.3,7.2,3.5 \mathrm{~Hz}, 1 \mathrm{H}, \mathrm{H}-5$ '), 3.30-3.20 (m, 1H, H-9), 2.75-2.57 (m, 2H, H-6'a, H-6'b), 2.22-2.15 (m, 3H, SC $2.04\left(\mathrm{~d}, J=2.5 \mathrm{~Hz}, 3 \mathrm{H}, \mathrm{CH}_{3} \mathrm{CO}\right), 2.00\left(\mathrm{~d}, J=9.4 \mathrm{~Hz}, 3 \mathrm{H}, \mathrm{CH}_{3} \mathrm{CO}\right), 1.95$ (d, $J=3.5$ $\left.\mathrm{Hz}, 3 \mathrm{H}, \mathrm{CH}_{3} \mathrm{CO}\right) .{ }^{13} \mathrm{C} \mathrm{NMR}\left(101 \mathrm{MHz}, \mathrm{CDCl}_{3}\right) \delta 170.22\left(\mathrm{CH}_{3} \underline{\mathrm{CO}}\right), 169.72\left(\mathrm{CH}_{3} \underline{\mathrm{CO}}\right)$, $169.24\left(\mathrm{CH}_{3} \underline{\mathrm{CO}}\right), 163.29$ (C-11), 148.09 (C-3), 132.79 (C-8), 125.42 (C-5), 118.92 
(C-10), 116.82 (C-6), 104.42 (C-4), 96.87 (C-1), 96.33 (C-1'), 74.94 (C-5'), 72.49 (C-3'), 71.41 (C-4'), 70.75 (C-2'), 69.50 (C-7), 45.32 (C-9), 35.73 (C-6'), 20.84 $\left.\left(\underline{\mathrm{CH}}_{3} \mathrm{CO}\right), 20.72\left(\underline{\mathrm{CH}}_{3} \mathrm{CO}\right), 20.63\left(\underline{\mathrm{CH}}_{3} \mathrm{CO}\right), 17.34\left(\mathrm{~S}_{\mathrm{CH}}\right)_{3}\right)$ HRMS (ESI): $m / z$ Calcd. for $\mathrm{C}_{23} \mathrm{H}_{28} \mathrm{SO}_{11} \mathrm{Na}[\mathrm{M}+\mathrm{Na}]^{+}$535.1239, found 535.1245 (1.0 ppm).

\subsubsection{2',3',4' -Tri-O-acetyl-6'-azido-6'-deoxy gentiopicroside (5c)}

$\mathrm{NaN}_{3}(8.1 \mathrm{mg}, 0.124 \mathrm{mmol}, 2.0$ equiv.) was added to a solution of the protected triflate residue 5 (38.0 mg, $0.062 \mathrm{mmol}, 1.0$ equiv.) in anhydrous DMF (2 mL). This reaction mixture was stirred at room temperature for $1 \mathrm{~h}$, and then the reaction mixture was diluted with Ethyl Acetate $(5 \mathrm{~mL})$ and washed with water $(5 \mathrm{~mL})$. The separated aqueous layer was washed with Ethyl Acetate $(2 \times 5 \mathrm{~mL})$. The combined organic layers were dried over anhydrous magnesium sulfate and concentrated in vacuum. The crude product was purified by column chromatography to give compound $\mathbf{5 c}(26.0 \mathrm{mg}, 83 \%)$ as a white foam. $\mathrm{R}_{\mathrm{f}}=0.46$ (Ethyl Acetate/Cyclohexane, 1:1). $[\alpha]_{D}^{20}=-110.0\left(\mathrm{c} 1.0, \mathrm{CHCl}_{3}\right) .{ }^{1} \mathrm{H} \mathrm{NMR}\left(400 \mathrm{MHz}, \mathrm{CDCl}_{3}\right): \delta 7.41(\mathrm{~d}, J=1.7$ $\mathrm{Hz}, 1 \mathrm{H}, \mathrm{H}-3), 5.63$ (ddd, $J=17.2,10.1,7.1 \mathrm{~Hz}, 1 \mathrm{H}, \mathrm{H}-8), 5.56$ (dt, $J=3.7,1.9 \mathrm{~Hz}$, $1 \mathrm{H}, \mathrm{H}-6), 5.43$ (d, $J=2.6 \mathrm{~Hz}, 1 \mathrm{H}, \mathrm{H}-1), 5.23$ (dd, $J=2.3,1.1 \mathrm{~Hz}, 1 \mathrm{H}, \mathrm{H}-2$ '), 5.22-5.20 (m, 1H, H-10a), 5.19 (d, J = 3.9 Hz, 1H, H-10b), 5.12-5.03 (m, 1H, H-3'), 4.99 (t, $J=2.0 \mathrm{~Hz}, 1 \mathrm{H}, \mathrm{H}-7 \mathrm{a}), 4.97$ (d, $J=3.8 \mathrm{~Hz}, 1 \mathrm{H}, \mathrm{H}-4$ '), 4.95-4.92 (m, 1H, H-7b), 4.89 (d, $J=8.1 \mathrm{~Hz}, 1 \mathrm{H}, \mathrm{H}-1^{\prime}$ ), 3.75 (ddd, $J=9.8,7.2,2.5 \mathrm{~Hz}, 1 \mathrm{H}, \mathrm{H}-5$ '), 3.42 (dd, $J=$ 13.4, 7.3 Hz, 1H, H-6'a), 3.33-3.13 (m, 2H, H-9, H-6'b), 2.03 (s, 3H, C${ }_{3} \mathrm{CO}$ ), 1.99 (s, $\left.3 \mathrm{H}, \mathrm{C}_{3} \mathrm{CO}\right), 1.94\left(\mathrm{~d}, \mathrm{~J}=3.0 \mathrm{~Hz}, 3 \mathrm{H}, \mathrm{CH}_{3} \mathrm{CO}\right) .{ }^{13} \mathrm{C} \mathrm{NMR}\left(101 \mathrm{MHz}, \mathrm{CDCl}_{3}\right): \delta$ $170.12\left(\mathrm{CH}_{3} \underline{\mathrm{CO}}\right), 169.62$ ( $\left.\mathrm{CH}_{3} \underline{\mathrm{CO}}\right), 169.15$ ( $\left.\mathrm{CH}_{3} \underline{\mathrm{CO}}\right), 163.24$ (C-11), 148.01 (C-3), 132.65 (C-8), 125.33 (C-5), 119.01 (C-10), 116.90 (C-6), 104.48 (C-4), 96.91 (C-1), 96.23 (C-1'), 74.19 (C-5'), 72.23 (C-2'), 70.56 (C-4'), 69.52 (C-3'), 69.51 (C-7), 51.07 (C-6'), 45.24 (C-9), 20.71 ( $\left.\underline{\mathrm{CH}}_{3} \mathrm{CO}\right), 20.67\left(\underline{\mathrm{CH}}_{3} \mathrm{CO}\right), 20.58$ ( $\left.\underline{\mathrm{CH}}_{3} \mathrm{CO}\right) . \mathrm{HRMS}$ (ESI): $m / z$ Calcd. for $\mathrm{C}_{22} \mathrm{H}_{25} \mathrm{NO}_{11} \mathrm{Na}[\mathrm{M}+\mathrm{Na}]^{+}$530.1381, found 530.1366 (3.0 ppm). 4.2.8. 2',3',4'-Tri-O-acetyl-6'-fluoro-6'-deoxy gentiopicroside (5d)

Tetrabutylammonium fluoride (1M in THF) $(205 \mu \mathrm{L}, 0.20 \mathrm{mmol}, 5.0$ equiv.) was slowly added to a solution of the protected triflate residue $5(25 \mathrm{mg}, 0.04 \mathrm{mmol}, 1.0$ 
equiv.) in dry THF $(2 \mathrm{~mL})$ at $0{ }^{\circ} \mathrm{C}$. The reaction mixture was then stirred at room temperature for $2 \mathrm{~h}$, diluted with Ethyl Acetate $(3 \mathrm{~mL})$ and washed with $1 \mathrm{M} \mathrm{HCl} \mathrm{(3}$ $\mathrm{mL})$. The combined aqueous phases were extracted once with Ethyl Acetate $(2 \times 5 \mathrm{~mL})$, and the combined organic phases washed with saturated sodium hydrogen carbonate $(5 \mathrm{~mL})$, water $(5 \mathrm{~mL})$, dried over anhydrous magnesium sulfate and concentrated under vacuum. The residue was purified by column chromatography (Ethyl Acetate/Cyclohexane, 2:1) to yield as a white foam $\mathbf{5 d}(12 \mathrm{mg}, 60 \%) . \mathrm{R}_{\mathrm{f}}=0.2$ (Ethyl Acetate/Cyclohexane, 2:3) $[\alpha]_{D}^{20}=-117.8$ (c $\left.0.5, \mathrm{CHCl}_{3}\right) .{ }^{1} \mathrm{H}$ NMR $(400 \mathrm{MHz}$, $\left.\mathrm{CDCl}_{3}\right): \delta 7.39(\mathrm{q}, J=1.4 \mathrm{~Hz}, 1 \mathrm{H}, \mathrm{H}-3), 5.65$ (ddd, $\left.J=17.3,10.3,7.1 \mathrm{~Hz}, 1 \mathrm{H}, \mathrm{H}-8\right)$, 5.59-5.54 (m, 1H, H-6), 5.45 (d, $J=2.4 \mathrm{~Hz}, 1 \mathrm{H}, \mathrm{H}-1), 5.27-5.23$ (m, 1H, H-3'), 5.23-5.21 (m, 1H, H-10a), 5.19 (d, $J=1.2 \mathrm{~Hz}, 1 \mathrm{H}, \mathrm{H}-10 \mathrm{~b}), 5.08$ (dd, $J=17.5,1.1 \mathrm{~Hz}$, 1H, H-7a), 5.02 (dd, $J=10.2,9.4$ Hz, 1H, H-4'), 4.99-4.95 (m, 1H, H-2'), 4.95-4.90 (m, 1H, H-7b), 4.88 (d, J = 8.0 Hz, 1H, H-1'), 4.58-4.48 (m, 1H, H-6'a), 4.46-4.36 (m, 1H, H-6'b), 3.77 (m, J = 20.9, 10.2, 4.6, 2.7 Hz, 1H, H-5'), 3.28 (dd, J = 7.0, 1.3 Hz, 1H, H-9), 2.04 (s, 3H, $\underline{\mathrm{H}}_{3} \mathrm{CO}$ ), 1.99 (s, 3H, $\left.\underline{\mathrm{CH}}_{3} \mathrm{CO}\right), 1.93$ (s, 3H, $\left.\underline{\mathrm{H}}_{3} \mathrm{CO}\right) .{ }^{13} \mathrm{C}$ NMR (101 MHz, $\left.\mathrm{CDCl}_{3}\right): \delta 170.23\left(\mathrm{CH}_{3} \underline{\mathrm{CO}}\right), 169.57\left(\mathrm{CH}_{3} \underline{\mathrm{CO}}\right), 169.17\left(\mathrm{CH}_{3} \underline{\mathrm{CO}}\right)$, 163.31 (C-11), 147.95 (C-3), 132.81 (C-8), 125.35 (C-5), 118.92 (C-10), 117.01 (C-6), 104.55 (C-4), 96.72 (C-1), 96.13 (C-1'), 82.13 (C-6’), 80.38 (C-6'), 73.26 (C-5'), 73.07 (C-5'), 72.46 (C-3'), 70.61 (C-2'), 69.56 (C-7), 68.04 (C-4'), 67.97 (C-4'), 45.26 (C-9), 20.75 ( $\left.\underline{\mathrm{CH}}_{3} \mathrm{CO}\right), 20.74\left(\underline{\mathrm{CH}}_{3} \mathrm{CO}\right), 20.64\left(\underline{\mathrm{CH}}_{3} \mathrm{CO}\right) .{ }^{19} \mathrm{~F}$ NMR $(376 \mathrm{MHz}$, $\mathrm{CDCl}_{3}$ ): $\delta$-74.52. HRMS (ESI): $\mathrm{m} / z$ Calcd. for $\mathrm{C}_{22} \mathrm{H}_{25} \mathrm{O}_{11} \mathrm{FNa}[\mathrm{M}+\mathrm{Na}]^{+}$507.1279, found $507.1273(-5.0 \mathrm{ppm})$.

\subsubsection{2',3',4'-Tri-O-acetyl-6'-bromo-6'-deoxy gentiopicroside (5e)}

Bromine ( $7 \mu \mathrm{L}, 0.14 \mathrm{mmol}, 2.0$ equiv.) was added dropwise to a stirred solution of the 4 (33.0 mg, $0.068 \mathrm{mmol}, 1.0$ equiv.) and triphenylphosphine (36.0 mg, $0.14 \mathrm{mmol}$, 2.0 equiv.) in anhydrous pyridine $(3 \mathrm{~mL})$ at $0{ }^{\circ} \mathrm{C}$. The mixture was allowed to warm to room temperature overnight. The solution was diluted with Ethyl Acetate $(10 \mathrm{~mL})$ and washed with saturated saturated sodium hydrogen carbonate solution $(5 \mathrm{~mL})$ and water $(5 \mathrm{~mL})$. The combined organic layers were dried over anhydrous magnesium 
sulfate and concentrated in vacuum. The crude product was purified by column chromatography to give compound $\mathbf{5 e}(23 \mathrm{mg}, 62 \%)$ as a white foam. $\mathrm{R}_{\mathrm{f}}=0.41$ (Ethyl Acetate/Cyclohexane, 1:1). $[\alpha]_{D}^{20}=-102.9\left(\mathrm{c} 1.0, \mathrm{CHCl}_{3}\right) .{ }^{1} \mathrm{H}$ NMR (400 MHz, $\left.\mathrm{CDCl}_{3}\right): \delta$ 7.45-7.35 (m, 1H, H-3), $5.66(\mathrm{ddd}, J=17.3,10.3,7.1 \mathrm{~Hz}, 1 \mathrm{H}, \mathrm{H}-8)$, 5.60-5.52 (m, 1H, H-6), 5.45 (d, J = 2.5 Hz, 1H, H-1), 5.26-5.23 (m, 1H, H-10a), 5.21 (s, 1H, H-10b), 5.19 (d, J=7.8 Hz, 1H, H-3'), 5.12-5.03 (m, 1H, H-7a), 4.99 (d, J = 4.1 Hz, 1H, H-4'), 4.98-4.95 (m, 4H, H-7b), 4.95-4.92 (m, 1H, H-2'), 4.88 (d, J = 8.1 Hz, 1H, H-1'), 3.75 (ddd, $J=9.7,7.0,2.6$ Hz, 1H, H-5'), 3.48 (dd, $J=11.4,2.6 \mathrm{~Hz}$, 1H, H-6'a), 3.38 (dd, $J=11.4,7.0 \mathrm{~Hz}, 1 \mathrm{H}, \mathrm{H}-6$ 'b), 3.30 (d, $J=6.4 \mathrm{~Hz}, 1 \mathrm{H}, \mathrm{H}-9$ ), 2.05 (s, 3H, $\left.\underline{\mathrm{H}}_{3} \mathrm{CO}\right), 2.00$ (s, 3H, $\left.\underline{\mathrm{H}}_{3} \mathrm{CO}\right), 1.95-1.92$ (m, 3H, $\left.\underline{\mathrm{H}}_{3} \mathrm{CO}\right) .{ }^{13} \mathrm{C} \mathrm{NMR}(101$ $\left.\mathrm{MHz}, \mathrm{CDCl}_{3}\right): \delta 170.20\left(\mathrm{CH}_{3} \underline{\mathrm{CO}}\right), 169.62\left(\mathrm{CH}_{3} \underline{\mathrm{CO}}\right), 169.20\left(\mathrm{CH}_{3} \underline{\mathrm{CO}}\right), 163.32(\mathrm{C}-11)$, 148.01 (C-3), 132.81 (C-8), 125.42 (C-5), 118.97 (C-10), 116.96 (C-6), 104.54 (C-4), 96.86 (C-1), 96.13 (C-1'), 73.71 (C-5'), 72.36 (C-3'), 70.96 (C-2'), 70.71 (C-4'), 69.57 (C-7), 45.25 (C-9), 30.62 (C-6), 20.84 ( $\left.\underline{\mathrm{CH}}_{3} \mathrm{CO}\right), 20.74\left(\underline{\mathrm{CH}}_{3} \mathrm{CO}\right), 20.65$ $\left(\underline{\mathrm{C}}_{3} \mathrm{CO}\right)$. HRMS (ESI): $\mathrm{m} / z$ Calcd. for $\mathrm{C}_{22} \mathrm{H}_{25} \mathrm{BrO}_{11} \mathrm{Na}[\mathrm{M}+\mathrm{Na}]^{+} 567.0487$, found $567.0472(-2.6 \mathrm{ppm})$.

\subsubsection{2',3',4'-Tri-O-acetyl-6'-iodo-6'-deoxy gentiopicroside (5f)}

Compound 4 (32.3 mg, $0.09 \mathrm{mmol}, 1.0$ equiv.) was dissolved in anhydrous toluene (5 mL), imdazole ( $2 \mathrm{mg}, 0.014 \mathrm{mmol}, 0.15$ equiv.), triphenylphosphere and iodine were sequence added after dissolution of each reagent. The mixture was heated under reflux at $70{ }^{\circ} \mathrm{C}$ for $15 \mathrm{~min}$, the reaction mixture was diluted with Ethyl Acetate $(10$ $\mathrm{mL})$ and washed with $\mathrm{Na}_{2} \mathrm{~S}_{2} \mathrm{O}_{3}(5 \mathrm{~mL})$. The combined organic layers were washed with brine $(5 \mathrm{~mL})$, dried over anhydrous magnesium sulfate, filtered and concentrated. The residue was purified by flash column chromatography (Ethyl Acetate/Cyclohexane, $1: 1)$ to give compound $\mathbf{5 f}(82.0 \mathrm{mg}, 53 \%)$ as a white foam. $\mathrm{R}_{\mathrm{f}}=$

0.39 (Ethyl Acetate/Cyclohexane, 1:1). $[\alpha]_{D}^{20}=-67.5$ (c 1.0, $\left.\mathrm{CHCl}_{3}\right) .{ }^{1} \mathrm{H} \mathrm{NMR}(400$ $\mathrm{MHz}, \mathrm{CDCl}_{3}$ ): $\delta$ 7.47-7.36 (m, 1H, H-3), 5.67 (ddd, $J=17.3,10.3,7.1 \mathrm{~Hz}, 1 \mathrm{H}, \mathrm{H}-8$ ), 5.61-5.54 (m, 1H, H-6), 5.47 (d, $J=2.6 \mathrm{~Hz}, 1 \mathrm{H}, \mathrm{H}-1), 5.31-5.24$ (m, 1H, H-10a), 5.24-5.21 (m, 1H, H-10b), 5.19 (d, $J=9.4$ Hz, 1H, H-3'), 5.12-5.04 (m, 1H, H-7a), 
5.01-4.96 (m, 1H, H-7b), 4.96-4.92 (m, 1H, H-2'), 4.90 (d, J = 6.2 Hz, 1H, H-1'), 4.88-4.85 (m, 1H, H-4'), 3.62-3.49 (m, 1H, H-5'), 3.31 (d, J = 2.6 Hz, 1H, H-9), 3.29 (d, $J=2.7 \mathrm{~Hz}, 1 \mathrm{H}, \mathrm{H}-6$ 'a), 3.15 (dd, $J=11.1,8.2 \mathrm{~Hz}, 1 \mathrm{H}, \mathrm{H}-6$ 'b), 2.05 (s, 3H, $\mathrm{C}_{3} \mathrm{CO}$ ), 1.99 (s, 3H, $\underline{\mathrm{CH}}_{3} \mathrm{CO}$ ), 1.94 (s, 3H, $\left.\underline{\mathrm{CH}}_{3} \mathrm{CO}\right) .{ }^{13} \mathrm{C} \mathrm{NMR}\left(101 \mathrm{MHz}, \mathrm{CDCl}_{3}\right.$ ): $\delta$ $170.20\left(\mathrm{CH}_{3} \underline{\mathrm{CO}}\right), 169.67\left(\mathrm{CH}_{3} \underline{\mathrm{CO}}\right), 169.25\left(\mathrm{CH}_{3} \underline{\mathrm{CO}}\right), 163.35$ (C-11), $148.11(\mathrm{C}-3)$, 132.85 (C-8), 125.48 (C-5), 119.02 (C-10), 116.92 (C-6), 104.53 (C-4), 97.02 (C-1), 96.18 (C-1'), 73.86 (C-5’), 72.21(C-3'), 72.16 (C-4'), 70.86 (C-2'), 69.59 (C-7), 45.28 (C-9), 20.88 ( $\left.\underline{\mathrm{CH}}_{3} \mathrm{CO}\right), 20.75$ ( $\left.\underline{\mathrm{CH}}_{3} \mathrm{CO}\right), 20.67$ ( $\left.\underline{\mathrm{CH}}_{3} \mathrm{CO}\right), 2.85$ (C-6'). HRMS (ESI): $m / z$ Calcd. for $\mathrm{C}_{22} \mathrm{H}_{25} \mathrm{IO}_{11} \mathrm{Na}[\mathrm{M}+\mathrm{Na}]^{+}$615.0333, found 615.0334 (0.2 ppm).

\subsubsection{6'-thio-6'-deoxy gentiopicroside (6a)}

Dibutyltin oxide (35.0 mg, $0.14 \mathrm{mmol}, 1.0$ equiv.) was added to a solution of the globe protected compound $\mathbf{5 a}(72.0 \mathrm{mg}, 0.14 \mathrm{mmol}, 1.0$ equiv.) in anhydrous methanol $(10 \mathrm{~mL})$. The mixture was heated under reflux at $70{ }^{\circ} \mathrm{C}$. The progress of the reaction was monitored with thin layer chromatography. Upon completion of the reaction, the mixture was evaporated to give a residue. Purification of the residue by flash column chromatography $\left(\mathrm{CH}_{2} \mathrm{Cl}_{2} / \mathrm{MeOH}, 95: 5\right)$ afforded the thio derivative $6 \mathbf{a}$

(36.7 mg, 74\%) as white foam. $\mathrm{R}_{\mathrm{f}}=0.42$ (Ethyl Acetate/Methanol, 5:1). $[\alpha]_{D}^{20}=-91.3$ (c 1.0, MeOH). ${ }^{1} \mathrm{H}$ NMR (400 MHz, $\left.\mathrm{D}_{2} \mathrm{O}\right): \delta 7.50$ (d, $\left.J=1.3 \mathrm{~Hz}, 1 \mathrm{H}, \mathrm{H}-3\right), 5.88-5.73$ (m, 1H, H-8), 5.67 (ddt, $J=4.4,2.7,1.5 \mathrm{~Hz}, 1 \mathrm{H}, \mathrm{H}-6$ ), 5.58 (d, $J=3.2 \mathrm{~Hz}, 1 \mathrm{H}, \mathrm{H}-1$ ), 5.35-5.22 (m, 2H, H-10a, H-10b), 5.20-4.97 (m, 2H, H-7a, H-7b), 4.77-4.65 (m, J = 7.9 Hz, 1H, H-1'), 3.43-3.31 (m, 4H, H-9, H-3', H-4', H-2'), 3.28-3.16 (m, 1H, H-5'), 3.09-2.95 (m, 1H, H-6'a), 2.71 (dd, $J=14.0,6.6 \mathrm{~Hz}, 1 \mathrm{H}, \mathrm{H}-6$ 'b). ${ }^{13} \mathrm{C}$ NMR (101 MHz, $\left.\mathrm{D}_{2} \mathrm{O}\right): \delta 167.77$ (C-11), 150.16 (C-3), 133.73 (C-8), 124.95 (C-5), 119.31 (C-10), 117.78 (C-6), 104.34 (C-4), 99.50 (C-1'), 98.65 (C-1), 76.91 (C-5'), 76.04 (C-2'), 73.26 (C-3'), 72.29 (C-4'), 71.21 (C-7), 45.28 (C-9), 25.77 (C-6'). HRMS (ESI): m/z Calcd. for $\mathrm{C}_{16} \mathrm{H}_{20} \mathrm{O}_{8} \mathrm{Na}[\mathrm{M}+\mathrm{Na}]^{+}$395.0777, found 395.0775 (0.5 ppm).

4.2.12. 6'-S-methyl-6'-thio -6'-deoxy gentiopicroside (6b)

Dibutyltin oxide (39.0 mg, $0.15 \mathrm{mmol}, 1.0$ equiv.) was added to a solution of the globe protected compound $\mathbf{5 b}(79.0 \mathrm{mg}, 0.15 \mathrm{mmol}, 1.0$ equiv.) in anhydrous 
methanol $(10 \mathrm{~mL})$. The mixture was heated under reflux at $70{ }^{\circ} \mathrm{C}$. The progress of the reaction was monitored with thin layer chromatography. Upon completion of the reaction, the mixture was evaporated to give a residue. Purification of the residue by flash column chromatography $\left(\mathrm{CH}_{2} \mathrm{Cl}_{2} / \mathrm{MeOH}, 95: 5\right)$ afforded the thio derivative $6 \mathbf{b}$ $(36.0 \mathrm{mg}, 60 \%)$ as white foam. $\mathrm{R}_{\mathrm{f}}=0.50$ (Ethyl Acetate $\left./ \mathrm{MeOH}, 5: 1\right) .[\alpha]_{D}^{20}=-101.8$

(c 1.0, MeOH). ${ }^{1} \mathrm{H}$ NMR (400 MHz, MeOD): $\delta 7.51$ (s, 1H, H-3), 5.87-5.72 (m, 1H, H-8), 5.67 (M, J = 6.1, 4.4, 2.5 Hz, 1H, H-6), 5.56 (d, J =3.2 Hz, 1H, H-1), 5.37-5.21 (m, 2H, H-10a, H-10b), 5.17-4.98 (m, 2H, H-7a, H-7b), 4.71 (d, J=7.9 Hz, 1H, H-1'), 3.62-3.46 (m, 1H, H-5'), 3.42-3.29 (m, 3H, H-3', H-4', H-9), 3.22 (dd, J = 9.0, 7.9 Hz, 1H, H-2'), 3.01 (dd, $J=14.2,2.4$ Hz, 1H, H-6'a), 2.78-2.64 (m, 1H, H-6'b), 2.20 (s, $\left.3 \mathrm{H}, \mathrm{CH}_{3}\right) .{ }^{13} \mathrm{C}$ NMR (101 MHz, MeOD): $\delta 166.18$ (C-11), 150.69 (C-3), 134.85 (C-8), 127.00 (C-5), 118.81 (C-10), 117.29 (C-6), 104.95 (C-4), 100.45 (C-1'), 98.88 (C-1), 78.01 (C-5'), 76.97 (C-3’), 74.53 (C-2’), 73.97 (C-4'), 70.89 (C-7), 46.70 (C-9), 36.76 (C-6'), $17.01\left(\underline{\mathrm{CH}}_{3}\right)$. HRMS (ESI): Calcd. for $\mathrm{C}_{17} \mathrm{H}_{22} \mathrm{O}_{8} \mathrm{SNa}[2 \mathrm{M}+\mathrm{Na}]^{+}$409.0933, found 409.0929 (0.4 ppm).

\subsubsection{6'-fluoro-6'-deoxy gentiopicroside (6d)}

Dibutyltin oxide (36.0 mg, $0.15 \mathrm{mmol}, 1.0$ equiv.) was added to a solution of the globe protected compound $\mathbf{5 d}(70.0 \mathrm{mg}, 0.15 \mathrm{mmol}, 1.0$ equiv.) in anhydrous methanol $(10 \mathrm{~mL})$. The mixture was heated under reflux at $70{ }^{\circ} \mathrm{C}$. The progress of the reaction was monitored with thin layer chromatography. Upon completion of the reaction, the mixture was evaporated to give a residue. Purification of the residue by flash column chromatography $\left(\mathrm{CH}_{2} \mathrm{Cl}_{2} / \mathrm{MeOH}, 90: 10\right)$ afforded the fluoro derivative 6d $\left(32.0 \mathrm{mg}, 62 \%\right.$ ) as white foam. $\mathrm{R}_{\mathrm{f}}=0.47$ (Ethyl Acetate/MeOH, 5:1). $[\alpha]_{D}^{20}=$ -159.4 (c 1.0, MeOH). ${ }^{1} \mathrm{H}$ NMR (400 MHz, MeOD): $\delta 7.49$ (d, $\left.J=1.3 \mathrm{~Hz}, 1 \mathrm{H}, \mathrm{H}-3\right)$, 5.78 (ddd, $J=17.3,10.3,7.0 \mathrm{~Hz}, 1 \mathrm{H}, \mathrm{H}-8$ ), 5.67 (dd, $J=3.7,2.7,1.5 \mathrm{~Hz}, 1 \mathrm{H}, \mathrm{H}-6$ ), 5.57 (d, $J=3.0 \mathrm{~Hz}, 1 \mathrm{H}, \mathrm{H}-1), 5.32-5.27$ (m, 1H, H-10a), 5.27-5.23 (m, 1H, H-10b), 5.12 (ddt, $J=17.6,2.5,1.2 \mathrm{~Hz}, 1 \mathrm{H}, \mathrm{H}-7 \mathrm{a}), 5.07-4.97$ (m, 1H, H-7b), 4.71 (d, $J=4.0$ Hz, 1H, H-1'), 4.62 (dd, $J=10.0,8.2 \mathrm{~Hz}, 1 \mathrm{H}, \mathrm{H}-6$ 'a), 4.60-4.55 (m, 1H, H-6'b), 3.58-3.47 (m, 1H, H-5'), 3.46-3.42 (m, 1H, H-3'), 3.41-3.39 (m, 1H, H-4'), 3.39 (d, J 
$=7.0 \mathrm{~Hz}, 1 \mathrm{H}, \mathrm{H}-9), 3.20\left(\mathrm{t}, J=8.5 \mathrm{~Hz}, 1 \mathrm{H}, \mathrm{H}-2{ }^{\prime}\right) .{ }^{13} \mathrm{C} \mathrm{NMR}(101 \mathrm{MHz}, \mathrm{MeOD}): \delta$ 166.36 (C-11), 150.65 (C-3), 135.00 (C-8), 127.03 (C-5), 118.80 (C-10), 117.44 (C-6), 105.11 (C-4), 100.42 (C-1'), 98.82 (C-1), 84.08 (C-6'), 82.38 (C-6'), 77.91 (C-3'), 76.88 (C-5'), 76.70 (C-5'), 74.49 (C-2'), 71.04 (C-7), 70.28 (C-4'), 70.21 (C-4'), 46.74 (C-9). ${ }^{19}$ F NMR (376 MHz, MeOD): $\delta$-80.04. HRMS (ESI): $m / z$ Calcd. for $\mathrm{C}_{16} \mathrm{H}_{19} \mathrm{FO}_{8} \mathrm{Na}[\mathrm{M}+\mathrm{Na}]^{+}$381.0962, found 381.0959 (0.3 ppm).

\subsubsection{6'-bromo-6'-deoxy gentiopicroside (6e)}

Dibutyltin oxide (36.0 mg, $0.14 \mathrm{mmol}, 1.0$ equiv.) was added to a solution of the globe protected compound 5e (78.0 $\mathrm{mg}, 0.14 \mathrm{mmol}, 1.0$ equiv.) in anhydrous methanol $(10 \mathrm{~mL})$. The mixture was heated under reflux at $70{ }^{\circ} \mathrm{C}$. The progress of the reaction was monitored with thin layer chromatography. Upon completion of the reaction, the mixture was evaporated to give a residue. Purification of the residue by flash column chromatography $\left(\mathrm{CH}_{2} \mathrm{Cl}_{2} / \mathrm{MeOH}, 95: 5\right)$ afforded the bromo derivative

6e $(40.0 \mathrm{mg}, 67 \%)$ as white foam. $\mathrm{R}_{\mathrm{f}}=0.29(\mathrm{DCM} / \mathrm{MeOH}, 9: 1) .[\alpha]_{D}^{20}=-109.0($ c 1.0 , MeOH). ${ }^{1} \mathrm{H}$ NMR (400 MHz, MeOD): $\delta 7.51$ (d, $\left.J=1.2 \mathrm{~Hz}, 1 \mathrm{H}, \mathrm{H}-3\right), 5.79$ (ddd, $J=$ 17.3, 10.3, 7.1 Hz, 1H, H-8), 5.73-5.65 (m, 1H, H-6), 5.58 (d, J = 3.1 Hz, 1H, H-1), 5.34-5.28 (m, 1H, H-10a), 5.28-5.24 (m, 1H, H-10b), 5.17-5.09 (m, 1H, H-7a), 5.08-5.00 (m, 1H, H-7b), 4.74 (d, $J=7.9 \mathrm{~Hz}, 1 \mathrm{H}, \mathrm{H}-1^{\prime}$ ), 3.83 (dd, $J=11.0,2.2 \mathrm{~Hz}$, 1H, H-6'a), 3.64-3.58 (m, 1H, H-6'b), 3.50 (ddd, $J=8.9,6.5,2.2$ Hz, 1H, H-5'), 3.41 (q, $J=8.2,7.5 \mathrm{~Hz}, 3 \mathrm{H}, \mathrm{H}-3$ ', H-9, H-4'), 3.22 (dd, $J=9.1,8.0 \mathrm{~Hz}, 1 \mathrm{H}, \mathrm{H}-2$ '). ${ }^{13} \mathrm{C}$ NMR (101 MHz, MeOD): $\delta 166.35$ (C-11), 150.69 (C-3), 135.01 (C-8), 127.09 (C-5), 118.83 (C-10), 117.43 (C-6), 105.10 (C-4), 100.37 (C-1'), 98.97 (C-1), 77.73 (C-3’), 76.77 (C-5'), 74.60 (C-2'), 73.50 (C-4'), 71.04 (C-7), 46.77 (C-9), 33.76 (C-6'). HRMS (ESI): $m / z$ Calcd. for $\mathrm{C}_{32} \mathrm{H}_{38} \mathrm{O}_{16} \mathrm{BrNa}[2 \mathrm{M}+\mathrm{Na}]^{+} 859.0429$, found 859.0419 $(-4.5 \mathrm{ppm})$.

\subsubsection{6'-iodo-6'-deoxy gentiopicroside (6f)}

Dibutyltin oxide (28.0 mg, $0.11 \mathrm{mmol}, 1.0$ equiv.) was added to a solution of the globe protected compound $\mathbf{5 f}(67.0 \mathrm{mg}, 0.11 \mathrm{mmol}, 1.0$ equiv.) in anhydrous methanol $(10 \mathrm{~mL})$. The mixture was heated under reflux at $70{ }^{\circ} \mathrm{C}$. The progress of the reaction 
was monitored with thin layer chromatography. Upon completion of the reaction, the mixture was evaporated to give a residue. Purification of the residue by flash column chromatography $\left(\mathrm{CH}_{2} \mathrm{Cl}_{2} / \mathrm{MeOH}, 95: 5\right)$ afforded the iodo derivative $6 \mathbf{f}(27.0 \mathrm{mg}, 51 \%)$ as white foam. $\mathrm{R}_{\mathrm{f}}=0.38$ (Ethyl Acetate/MeOH, 5:1). $[\alpha]_{D}^{20}=-71.1(\mathrm{c} 1.0, \mathrm{MeOH}) .{ }^{1} \mathrm{H}$ NMR (400 MHz, MeOD): $\delta 7.51$ (d, $J=1.3 \mathrm{~Hz}, 1 \mathrm{H}, \mathrm{H}-3), 5.79$ (ddd, $J=17.3,10.3$, $7.2 \mathrm{~Hz}, 1 \mathrm{H}, \mathrm{H}-8$ ), 5.68 (ddt, $J=4.4,2.8,1.5 \mathrm{~Hz}, 1 \mathrm{H}, \mathrm{H}-6), 5.61$ (d, $J=3.3 \mathrm{~Hz}, 1 \mathrm{H}$, H-1), 5.35-5.29 (m, 1H, H-10a), 5.29-5.25 (m, 1H, H-10b), 5.19-4.99 (m, 2H, H-7a, H-7b), 4.73 (d, $J=8.0 \mathrm{~Hz}, 1 \mathrm{H}, \mathrm{H}-1^{\prime}$ ), 3.66 (dd, $J=10.7,1.8 \mathrm{~Hz}, 1 \mathrm{H}, \mathrm{H}-6$ 'a), 3.45-3.37 (m, 3H, H-9, H-5', H-6'b), 3.30-3.16 (m, 3H, H-3', H-2', H-4'). ${ }^{13} \mathrm{C}$ NMR (101 MHz, MeOD): $\delta 166.30$ (C-11), 150.77 (C-3), 135.05 (C-8), 127.19 (C-5), 118.89 (C-10), 117.38 (C-6), 105.10 (C-4), 100.40 (C-1'), 99.10 (C-1), 77.56 (C-5'), 76.76 (C-2'), 75.26 (C-3'), 74.74 (C-4'), 71.04 (C-7), 46.83 (C-9), 6.63 (C-6'). HRMS (ESI): $\mathrm{m} / \mathrm{z}$ Calcd. for $\mathrm{C}_{32} \mathrm{H}_{38} \mathrm{O}_{16} \mathrm{INa}[2 \mathrm{M}+\mathrm{Na}]^{+}$955.0153, found 955.0141 (-1.2 ppm).

\subsubsection{2',3',4'-Tri-O-acetyl-6'-acetamido-6'-deoxy gentiopicroside (7)}

To a solution of $\mathbf{5 c}(280 \mathrm{mg}, 0.58 \mathrm{mmol}, 1.0$ equiv.) in THF (10 mL) and water (0.2 mL) was added $\mathrm{PPh}_{3}$ (305mg, $1.16 \mathrm{mmol}, 2.0$ equiv.). The reaction mixture was reacted at $50{ }^{\circ} \mathrm{C}$ for $7 \mathrm{~h}$, the mixture was evaporated under diminished pressure, and the residue was used directly in the next step without further purification. $R_{\mathrm{f}}=0.37$ ( DCM/MeOH, 95:5).

Acetia anhydride $(0.17 \mathrm{~mL}, 1.74 \mathrm{mmol}, 3.0$ equiv. $)$ was added to a solution of the residue in anhydrous pyridine $(5 \mathrm{~mL})$ and then stirred at room temperature under nitrogen for overnight. The solution was evaporated in vacuum, then dissolved in $\mathrm{CH}_{2} \mathrm{Cl}_{2}(30 \mathrm{~mL})$, washed with water $(20 \mathrm{~mL})$, saturated sodium hydrogen carbonate solution $(20 \mathrm{~mL})$ and brine $(20 \mathrm{~mL})$. The organic phase was dried anhydrous magnesium sulfate, filtered and concentrated. The residue was purified by flash column chromatography (DCM/MeOH, 97:3) to give compound 7 (273 mg, 90\% in two steps) as a yellow foam. $\mathrm{R}_{\mathrm{f}}=0.13(\mathrm{DCM} / \mathrm{MeOH}, 97: 3) .[\alpha]_{D}^{20}=-110.4$ (c 1.0, $\left.\mathrm{CHCl}_{3}\right) .{ }^{1} \mathrm{H}$ NMR (400 MHz, $\left.\mathrm{CDCl}_{3}\right): \delta 7.36(\mathrm{~s}, J=1.3 \mathrm{~Hz}, 1 \mathrm{H}, \mathrm{H}-3), 5.85(\mathrm{t}, J=6.1$ 
Hz, 1H, N吕c), 5.63 (ddd, $J=17.3,10.3,7.1 \mathrm{~Hz}, 1 \mathrm{H}, \mathrm{H}-8), 5.55$ (m, $J=4.4,2.6,2.1$, $1.2 \mathrm{~Hz}, 1 \mathrm{H}, \mathrm{H}-6), 5.39$ (d, J = 2.4 Hz, 1H, H-1), 5.22 (dt, J=7.1, 1.2 Hz, 1H, H-10a), 5.20-5.18 (m, 1H, H-10b), 5.16 (d, $J=9.5 \mathrm{~Hz}, 1 \mathrm{H}, \mathrm{H}-3$ ') 5.05 (dd, $J=17.6,2.4 \mathrm{~Hz}$, 1H, H-7a), 4.98-4.92 (m, 1H, H-7b), 4.92-4.89 (m, 1H, H-4'), 4.89-4.85 (m, 1H, H-2'), 4.83 (d, $J=8.1 \mathrm{~Hz}, 1 \mathrm{H}, \mathrm{H}-1^{\prime}$ ), 3.62 (ddd, $J=10.0,4.4,3.2 \mathrm{~Hz}, 1 \mathrm{H}, \mathrm{H}-5$ ') 3.50 (ddd, $J=6.3,3.8,2.1 \mathrm{~Hz}, 2 \mathrm{H}, \mathrm{H}-6 \mathrm{a}^{\prime}, \mathrm{H}-6 \mathrm{~b}^{\prime}$ ), 3.24 (ddd, $J=6.2,2.5,1.2 \mathrm{~Hz}, 1 \mathrm{H}, \mathrm{H}-9$ ), 2.02 (s, 3H, $\left.\mathrm{NHCH}_{3} \mathrm{CO}\right), 1.96$ (d, J=4.1 Hz, 6H, $\left.\underline{\mathrm{H}}_{3} \mathrm{CO}\right), 1.90$ (s, 3H, $\left.\underline{\mathrm{H}}_{3} \mathrm{CO}\right) .{ }^{13} \mathrm{C}$ NMR (101 MHz, $\left.\mathrm{CDCl}_{3}\right): \delta$ 170.28-169.77 (3× $\left.\mathrm{CH}_{3} \underline{\mathrm{CO}}\right), 169.15\left(\mathrm{NHCH}_{3} \underline{\mathrm{CO}}\right), 163.14$ (C-11), 147.83 (C-3), 132.70 (C-8), 125.22 (C-5), 118.83 (C-10), 116.93 (C-6), 104.42 (C-4), 96.70 (C-1), 96.24 (C-1'), 73.03 (C-5'), 72.26 (C-3'), 70.58 (C-4'), 69.41 (C-7), 68.55 (C-2'), 45.18 (C-9), 38.86 (C-6'), $23.29\left(\underline{\mathrm{CH}}_{3} \mathrm{CO}\right), 20.81-20.42$

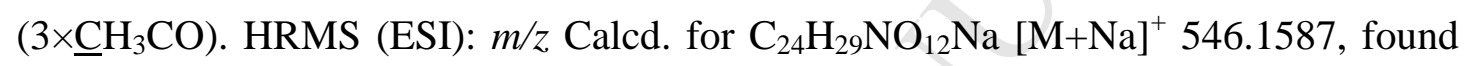
546.1585 ( $0.3 \mathrm{ppm})$.

\subsubsection{6'-acetamido-6'-deoxy gentiopicroside (8)}

Dibutyltin oxide (153 mg, $0.62 \mathrm{mmol}, 1.5$ equiv.) was added to a solution of the globe protected compound 7 (214 mg, $0.41 \mathrm{mmol}, 1.0$ equiv.) in anhydrous methanol $(10 \mathrm{~mL})$. The mixture was heated under reflux at $70{ }^{\circ} \mathrm{C}$. The progress of the reaction was monitored with thin layer chromatography. Upon completion of the reaction, the mixture was evaporated to give a residue. Purification of the residue by flash column chromatography $\left(\mathrm{CH}_{2} \mathrm{Cl}_{2} / \mathrm{MeOH}, 83: 17\right)$ afforded the compound $8(74 \mathrm{mg}, 46 \%)$ as white foam. $\mathbf{R}_{\mathbf{f}}=0.26\left(\right.$ DCM/Methanol, 9:1). $[\alpha]_{D}^{20}=-95.8$ (c 1.0, MeOH). ${ }^{1} \mathrm{H}$ NMR (400 MHz, MeOD): $\delta 7.52$ (s, 1H, H-3), 5.82 (ddd, $J=17.3,10.3,7.0 \mathrm{~Hz}, 1 \mathrm{H}, \mathrm{H}-8$ ), 5.74-5.68 (m, 1H, H-6), 5.67 (d, J=3.1 Hz, 1H, H-1), 5.35-5.26 (m, 2H, H-7a, H-7b), $5.15(\mathrm{dd}, J=17.7,2.7,1.3 \mathrm{~Hz}, 1 \mathrm{H}, \mathrm{H}-10 \mathrm{a}), 5.06(\mathrm{dd}, J=17.7,3.5,1.2 \mathrm{~Hz}, 1 \mathrm{H}$, H-10b), 4.77-4.67 (d, J = 8.9 Hz, 1H, H-1'), 3.73-3.64 (m, 1H, H-6'a), 3.60-3.45 (m, 2H, H-6'b, H-3'), 3.40-3.35 (m, 1H, H-5'), 3.29-3.18 (m, 2H, H-4', H-2'), 2.04 (s, 3H, $\left.\mathrm{C}_{3}\right) .{ }^{13} \mathrm{C}$ NMR (101 MHz, MeOD): $\delta 173.37$ ( $\left.\mathrm{CH}_{3} \underline{\mathrm{CO}}\right), 166.17$ (C-11), 150.57 (C-3), 134.93 (C-8), 127.00 (C-5), 118.61 (C-10), 117.20 (C-6), 104.94 (C-4), 100.22 (C-1), 98.53 (C-1'), 77.39 (C-3'), 76.33 (C-5), 74.63 (C-4'), 72.64 (C-2'), 70.87 (C-7), 46.65 
(C-9), 41.61 (C-6'), $22.47\left(\underline{\left.\mathrm{CH}_{3}\right)}\right.$. HRMS (ESI): $\mathrm{m} / z$ Calcd. for $\mathrm{C}_{16} \mathrm{H}_{20} \mathrm{O}_{8} \mathrm{Na}[\mathrm{M}+\mathrm{Na}]^{+}$ 395.0777, found $395.0771(0.5 \mathrm{ppm})$.

\subsubsection{6'-O-Triisopropylsilyl gentiopicroside (9)}

Gentiopicrin (32.3 mg, $0.09 \mathrm{mmol}, 1.0$ equiv.) and Imidazole (18.4 mg, $0.27 \mathrm{mmol}$, 3.0 equiv.) were dissolved in anhydrous DMF ( $2 \mathrm{~mL})$ and then DMAP $(2 \mathrm{mg}, 0.014$ mmol, 0.15 equiv.) was added. The reaction mixture cooled to $0{ }^{\circ} \mathrm{C}$. TIPSCl $(41 \mu \mathrm{L}$, 0.19 mmol, 2.1 equiv.) was slowly added and then the reaction mixture was allowed to warm to room temperature. After $16 \mathrm{~h}$ the reaction mixture was washed with water and the aqueous layer extracted with Ethyl Acetate $(2 \times 5 \mathrm{~mL})$. The combined organic layers were washed with brine $(5 \mathrm{~mL})$, dried over anhydrous magnesium sulfate, filtered and concentrated. The residue was purified by flash column chromatography (Ethyl Acetate/Cyclohexane/MeOH, 5:5:1) to give compound 9 (42.6 mg, 92\%) as a white foam. $\mathbf{R}_{\mathbf{f}}=0.35$ (Ethyl Acetate/Cyclohexane/MeOH, 5:5:1). $[\alpha]_{D}^{20}=-123.1(\mathrm{c}$ 1.0, MeOH). ${ }^{1} \mathrm{H}$ NMR (400 MHz, Acetone-d $\left.{ }_{6}\right): \delta 7.36$ (s, $\left.J=1.4 \mathrm{~Hz}, 1 \mathrm{H}, \mathrm{H}-3\right)$, 5.77-5.67 (m, 1H, H-8), 5.65 (ddd, $J=3.2,2.5,1.3 \mathrm{~Hz}, 1 \mathrm{H}, \mathrm{H}-6), 5.54$ (d, $J=2.9 \mathrm{~Hz}$, 1H, H-1), 5.30-5.16 (m, 2H, H-10a, H-10b), 5.08-4.90 (m, 2H, H-7a, H-7b), 4.67 (d, J = 7.9 Hz, 1H, H-1'), 4.11 (dd, $J=10.9,1.6 \mathrm{~Hz}, 1 \mathrm{H}, \mathrm{H}-6$ 'a), 3.97-3.82 (m, 1H, H-6’b), 3.47-3.34 (m, 3H, H-5', H-3', H-4'), 3.26 (dd, J = 7.3, 2.8, 1.4 Hz, 1H, H-9), 3.19 (t, J $\left.=8.3 \mathrm{~Hz}, 1 \mathrm{H}, \mathrm{H}-2^{\prime}\right), 1.20-1.01\left(\mathrm{~m}, 21 \mathrm{H}, 3 \times\left(\mathrm{CH}_{3}\right)_{2} \mathrm{C} \underline{\mathrm{H}}\right) .{ }^{13} \mathrm{C} \mathrm{NMR}(101 \mathrm{MHz}$, Acetone- $\left.\mathrm{d}_{6}\right): \delta 163.36$ (C-11), 149.22 (C-3), 134.89 (C-8), 126.51 (C-5), 118.21 (C-10), 117.03 (C-6), 104.77 (C-4), 99.99 (C-1'), 97.87 (C-1), 78.18 (C-5'), 77.86 (C-3’), 74.22 (C-2'), 70.90 (C-4'), 69.85 (C-7), 64.15 (C-6’), 46.27 (C-9), 18.37 $\left(\underline{\mathrm{CH}}_{3}\right), 12.72(\underline{\mathrm{CH}})$. HRMS (ESI): $\mathrm{m} / z$ Calcd. for $\mathrm{C}_{25} \mathrm{H}_{40} \mathrm{O}_{9} \mathrm{SiNa}[\mathrm{M}+\mathrm{Na}]^{+} 535.2342$, found $535.2334(-1.6 \mathrm{ppm})$.

\subsubsection{2',3',4'-Tri-O-benzoyl-6'-O-Triisopropylsilyl gentiopicroside (10)}

Benzoyl chloride (0.33 mL, $2.8 \mathrm{mmol}, 5.0$ equiv.) was added dropwise to a stirring mixture of 9 (288.5 mg, $0.56 \mathrm{mmol}, 1.0$ equiv.) in anhydrous pyridine (10 mL) under an argon atmosphere at room temperature, and then DMAP (6.8 mg, $0.056 \mathrm{mmol}, 0.1$ equiv.) was added, the reaction mixture was stirred for $20 \mathrm{~h}$ at room temperature. The mixture was quenched with saturated sodium hydrogen carbonate solution $(5 \mathrm{~mL})$ and 
the aqueous phase was extracted with Ethyl Acetate $(2 \times 10 \mathrm{~mL})$. The combined organic layers were washed with brine $(5 \mathrm{~mL})$, dried over anhydrous magnesium sulfate, filtered and concentrated. The residue was purified by flash column chromatography (Ethyl Acetate/Cyclohexane, 1:4) to give compound 10 (431.0 mg, $93 \%$ ) as a white foam. $\mathrm{R}_{\mathrm{f}}=0.40$ (Ethyl Acetate/Cyclohexane, 1:2). $[\alpha]_{D}^{20}=-96.7(\mathrm{c}$ 1.0, $\left.\mathrm{CHCl}_{3}\right) .{ }^{1} \mathrm{H} \mathrm{NMR}\left(400 \mathrm{MHz}, \mathrm{CDCl}_{3}\right): \delta 7.94-7.27(\mathrm{~m}, 15 \mathrm{H}, \mathrm{H}$ arom), $7.22(\mathrm{~d}, J=$ $1.5 \mathrm{~Hz}, 1 \mathrm{H}, \mathrm{H}-3$ ), 5.86 (t, J = 9.7 Hz, 1H, H-3'), 5.65-5.57 (m, 1H, H-8), 5.56-5.51 (m, 2H, H-4', H-1), 5.48-5.40 (m, 2H, H-2',H-6), 5.19 (dt, J = 3.7, $1.2 \mathrm{~Hz}, 1 \mathrm{H}, \mathrm{H}-10 \mathrm{a}$ ), 5.17-5.11 (m, 2H, H-10b, H-1'), 4.71 (ddt, $J=17.4,3.9,1.0$ Hz, 1H, H-7a), 4.47 (ddt, $J=17.4,2.3,1.0$ Hz, 1H, H-7b), 3.98-3.89 (m, 3H, H-6'a, H-6'b, H-5'), 3.28-3.14 (m, 1H, H-9), 1.13-1.03 (m, 18H, $\left.\underline{\mathrm{H}}_{3}\right), 1.03-0.96$ (m, 3H, C$) . ~{ }^{13} \mathrm{C}$ NMR (101 MHz, $\left.\mathrm{CDCl}_{3}\right): \delta 165.91$ (PhCO), 165.31 (Phㅁ), 165.20 (PhC्O), 162.82 (C-11), 147.69 (C-3), 133.82-128.47 (C arom), 133.00 (C-8), 125.57 (C-5), 118.65 (C-10), 116.75 (C-6), 104.29 (C-4), 96.35 (C-1), 96.13 (C-1'), 76.12 (C-5'), 73.02 (C-3’), 71.52 (C-2'), 69.60 (C-4'), 68.98 (C-7), 62.91 (C-6'), 45.18 (C-9), 18.08 (3× CH$_{3}$ ), 12.16

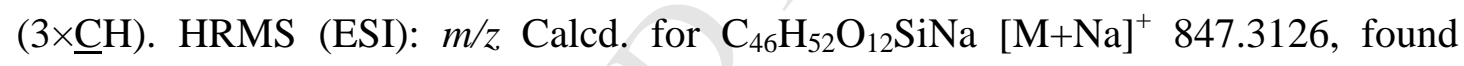
$847.3105(2.0 \mathrm{ppm})$.

\subsubsection{2',3',6'-Tri-O-benzoyl gentiopicroside (11)}

Compound 10 (275.7 mg, $0.34 \mathrm{mmol}, 1.0$ equiv.) was stirred with TBAF $1.0 \mathrm{M}$ $\left(0.25 \mathrm{~mL}, 0.25 \mathrm{mmol}, 0.7\right.$ equiv.) at $0^{\circ} \mathrm{C}$ under argon. After $15 \mathrm{~min}, 0.25 \mathrm{ml}$ of TBAF 1.0 $\mathrm{M}$ was added again and the mixture was stirred for an additional $30 \mathrm{~min}$ at $0{ }^{\circ} \mathrm{C}$. Then quenched with the addition of saturated aqueous sodium hydrogen carbonate ( 5 $\mathrm{mL})$ and extracted with Ethyl Acetate $(2 \times 5 \mathrm{~mL})$. The combined organic layers were washed with saturated aqueous brine $(5 \mathrm{~mL})$, dried over anhydrous magnesium sulfate, and concentrated in vacuum. The residue was purified by flash column chromatography (Ethyl Acetate/Cyclohexane, 1:3) to give compound 11 (154.5 mg, $70 \%$ ) as a white foam. $\mathrm{R}_{\mathrm{f}}=0.29$ (Ethyl Acetate/Cyclohexane, $\left.2: 3\right) .[\alpha]_{D}^{20}=-87.5(\mathrm{c}$ 1.0, $\left.\mathrm{CHCl}_{3}\right) .{ }^{1} \mathrm{H} \mathrm{NMR}\left(400 \mathrm{MHz}, \mathrm{CDCl}_{3}\right): \delta 8.24-7.32$ (m, $15 \mathrm{H}, \mathrm{H}$ arom), $7.20(\mathrm{~s}, 1 \mathrm{H}$, H-3), 5.58 (ddd, $J=17.2,10.1,7.0 \mathrm{~Hz}, 1 \mathrm{H}, \mathrm{H}-8), 5.52-5.45$ (m, 2H, H-1, H-3'), 5.41 
(t, $J=8.9 \mathrm{~Hz}, 2 \mathrm{H}, \mathrm{H}-6, \mathrm{H}-2$ '), 5.16 (d, $J=5.5 \mathrm{~Hz}, 1 \mathrm{H}, \mathrm{H}-10 \mathrm{a}), 5.14-5.03$ (m, 2H, H-10b, H-1'), 4.78 (dd, $J=12.2,4.0$ Hz, 1H, H-6a), 4.73-4.59 (m, 2H, H-6b, H-7a), 4.45-4.30 (m, 1H, H-7b), 4.00-3.92 (m, 1H, H-4'), 3.88 (ddd, $J=9.8,4.0,2.2 \mathrm{~Hz}, 1 \mathrm{H}$, H-5'), 3.67 (d, $J=4.2 \mathrm{~Hz}, 1 \mathrm{H}, \mathrm{OH}), 3.21$ (d, $J=6.7 \mathrm{~Hz}, 1 \mathrm{H}, \mathrm{H}-9) .{ }^{13} \mathrm{C}$ NMR (101

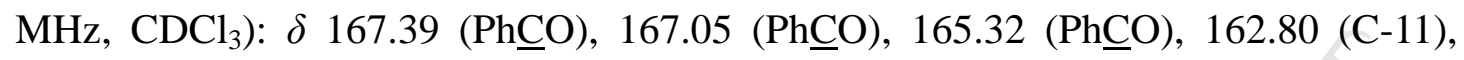
147.55 (C-3), 133.92-128.64 (C arom), 132.83 (C-8), 125.46 (C-5), 118.70 (C-10), 116.75 (C-6), 104.28 (C-4), 96.13 (C-1), 95.92 (C-1'), 76.25 (C-3'), 75.15 (C-5'), 70.85 (C-2'), 69.66 (C-4'), 68.92 (C-7), 63.28 (C-6'), 44.96 (C-9). HRMS (ESI): m/z Calcd. for $\mathrm{C}_{37} \mathrm{H}_{32} \mathrm{O}_{12} \mathrm{Na}[\mathrm{M}+\mathrm{Na}]^{+}$691.1768, found 691.1786 (2.5 ppm).

\subsubsection{2',3',6'-Tri-O-benzoyl-4'- O-methylsulfonyl gentiopicroside (11a)}

Methanesulfonyl chloride $(6 \mu \mathrm{L}, 0.078 \mathrm{mmol}, 2.0$ equiv.) was added dropwise at $0{ }^{\circ} \mathrm{C}$ to a stirred solution of $\mathbf{1 1}\left(26 \mathrm{mg}, 0.039 \mathrm{mmol}, 1.0\right.$ equiv.) in $\mathrm{CH}_{2} \mathrm{Cl}_{2}(3 \mathrm{~mL})$. After 2 min, pyridine $(100 \mu \mathrm{L})$ was added to this stirred solution at the same temperature. After $40 \mathrm{~min}$, the reaction mixture was diluted with $\mathrm{CH}_{2} \mathrm{Cl}_{2}(5 \mathrm{~mL})$ and washed successively with $1 \mathrm{M} \mathrm{HCl}(2 \mathrm{~mL})$, saturated aqueous $\mathrm{NaHCO}_{3}(5 \mathrm{~mL})$ and water $(5 \mathrm{~mL})$. The separated organic layer was dried over $\mathrm{MgSO}_{4}$ and concentrated in vacuum. The residue was purified by flash column chromatography (Ethyl Acetate/Cyclohexane, 1:3) to give compound 11a (26.5 mg, 92\%) as a yellow foam.

$\mathrm{R}_{\mathrm{f}}=0.38$ (Ethyl Acetate/Cyclohexane, 1:1). $[\alpha]_{D}^{20}=-57.89$ (c 1.0, $\mathrm{CHCl}_{3}$ ). ${ }^{1} \mathrm{H} \mathrm{NMR}$ (400 MHz, $\left.\mathrm{CDCl}_{3}\right): \delta 8.18-7.25(\mathrm{~m}, 15 \mathrm{H}, \mathrm{H}$ arom), 7.23-7.16 (s, 1H, H-3), $5.81(\mathrm{t}, J=$ $9.6 \mathrm{~Hz}, 1 \mathrm{H}, \mathrm{H}-3$ ') , 5.64-5.50 (m, 1H, H-8), 5.50-5.46 (d, 1H, H-1), 5.46-5.39 (m, 2H, H-2', H-6), 5.23-5.06 (m, 3H, H-4', H-10, H-1'), 4.84 (dd, $J=12.5,2.2 \mathrm{~Hz}, 1 \mathrm{H}$, H-6'a), 4.73-4.63 (m, 1H, H-7a), 4.63-4.53 (m, 1H, H-6'b), 4.40 (d, J = 17.5 Hz, 1H, H-7b), 4.07 (ddd, $J=9.9,4.0,2.2 \mathrm{~Hz}, 1 \mathrm{H}, \mathrm{H}-5$ '), 3.20 (d, J = 6.9 Hz, 1H, H-9), 2.88 (s, 3H, $\left.\underline{\mathrm{CH}}_{3}\right) .{ }^{13} \mathrm{C}$ NMR (101 MHz, $\mathrm{CDCl}_{3}$ ): $\delta 166.19$ (PhCOO), 165.63 (PhCO), 164.96 (PhCOO), 162.52 (C-11), 147.25 (C-3), 133.88-128.33(C arom), 132.59 (C-8), 125.27 (C-5), 118.79 (C-10), 116.88 (C-6), 104.36 (C-4), 96.14 (C-1), 95.79 (C-1'), 74.17 (C-4'), 72.77 (C-5'), 72.05 (C-3’), 71.01 (C-2’), 68.88 (C-7), 61.99 (C-6'), 44.83 (C-9), $38.94\left(\underline{\mathrm{CH}}_{3}\right)$. HRMS (ESI): $m / z$ Calcd. for $\mathrm{C}_{37} \mathrm{H}_{32} \mathrm{O}_{12} \mathrm{Na}[\mathrm{M}+\mathrm{Na}]^{+} 769.1529$, 
found $769.1561(4.2 \mathrm{ppm})$.

\subsubsection{2',3',6'-Tri-O-benzyl gentiopicroside (12a)}

Potassium nitrite (11.2 $\mathrm{mg}, 0.11 \mathrm{mmol}, 5.0$ equiv.) was added to a solution of the protected triflate residue 12 in dry DMF $(3 \mathrm{~mL})$. After stirring at $50{ }^{\circ} \mathrm{C}$ for $2 \mathrm{~h}$, the mixture was diluted with Ethyl Acetate $(2 \times 5 \mathrm{~mL})$ and washed with brine $(5 \mathrm{~mL})$. The organic phase was dried with anhydrous magnesium sulfate and concentrated in vacuum. Purification of the residue by flash column chromatography (Ethyl Acetate/Cyclohexane, 1:3) afforded the inversion products 12a (22 mg, 81\% in two

steps). $\mathrm{R}_{\mathrm{f}}=0.29$ (Ethyl Acetate/Cyclohexane, 2:3). $[\alpha]_{D}^{20}=-97.2\left(\mathrm{c} 1.0, \mathrm{CHCl}_{3}\right) .{ }^{1} \mathrm{H}$ NMR (400 MHz, $\left.\mathrm{CDCl}_{3}\right): \delta 8.06-7.29(\mathrm{~m}, 15 \mathrm{H}, \mathrm{H}$ arom), $7.18(\mathrm{~d}, J=1.5 \mathrm{~Hz}, 1 \mathrm{H}$, H-3), 5.79 (dd, $J=10.4,8.1 \mathrm{~Hz}, 1 \mathrm{H}, \mathrm{H}-2$ ') , 5.62-5.55 (m, 1H, H-8), 5.55-5.52 (m, 1H, H-1), 5.40 (m, $J=3.8,2.2 \mathrm{~Hz}, 1 \mathrm{H}, \mathrm{H}-6), 5.35$ (dd, $J=10.4,3.2 \mathrm{~Hz}, 1 \mathrm{H}, \mathrm{H}-3$ '), 5.15 (dt, $J=4.4,1.2 \mathrm{~Hz}, 1 \mathrm{H}, \mathrm{H}-10 \mathrm{a}), 5.11$ (dt, $J=2.7,1.2 \mathrm{~Hz}, 1 \mathrm{H}, \mathrm{H}-10 \mathrm{~b}), 5.06$ (d, $J=8.1$ Hz, 1H, H-1'), 4.70 (dd, $J=11.5,6.3$ Hz, 1H, H-6'a), 4.66-4.63 (m, 1H, H-6'b), 4.63-4.56 (m, 1H, H-7a), 4.47-4.39 (m, 1H, H-4'), 4.35 (ddt, $J=17.4,2.3,0.9 \mathrm{~Hz}, 1 \mathrm{H}$, H-7b), 4.19-4.10 (m, J = 6.3 Hz, 1H, H-5'), 3.27-3.18 (m, 1H, H-9), 3.14 (d, $J=4.8$ $\mathrm{Hz}, 1 \mathrm{H}, \mathrm{O} \underline{\mathrm{H}}) .{ }^{13} \mathrm{C} \mathrm{NMR}\left(101 \mathrm{MHz}, \mathrm{CDCl}_{3}\right): \delta 166.51$ (PhCO), 165.81 (PhCO), 165.30 (Ph므), 162.80 (C-11), 147.40 (C-3), 133.69-128.49 (C arom), 132.87 (C-8), 125.29 (C-5), 118.44 (C-10), 116.68 (C-6), 104.16 (C-4), 96.06 (C-1'), 95.87 (C-1), 73.82 (C-3'), 73.06 (C-5'), 68.84 (C-7), 68.82 (C-2'), 67.09 (C-4'), 62.81 (C-6’), 44.85 (C-9). HRMS (ESI): $m / z$ Calcd. for $\mathrm{C}_{37} \mathrm{H}_{32} \mathrm{O}_{12} \mathrm{Na}[\mathrm{M}+\mathrm{Na}]^{+}$691.1791, found $691.1811(-4.5 \mathrm{ppm})$.

\subsubsection{2',3',6'-Tri-O-benzoyl-4'-S-acetyl-4'-thio-4'-deoxy gentiopicroside (12b)}

Potassium thioacetate $(6.5 \mathrm{mg}, 0.057 \mathrm{mmol}, 3.0$ equiv.) was added to a solution of the protected triflate residue $12(15 \mathrm{mg}, 0.02 \mathrm{mmol}, 1.0$ equiv.) in anhydrous DMF (3 $\mathrm{mL}$ ). After stirring at room temperature for $2 \mathrm{~h}$, the mixture was diluted with Ethyl Acetate $(2 \times 5 \mathrm{~mL})$, washed with brine $(5 \mathrm{~mL})$. The organic phase was dried over anhydrous magnesium sulfate and concentrated in vacuum. Purification of the residue by flash column chromatography (Ethyl Acetate/cyclohexane, 1:1) afforded the 
thiolacetate derivative $\mathbf{1 2 b}\left(24 \mathrm{mg}, 88 \%\right.$ in two steps). $\mathrm{R}_{\mathrm{f}}=0.46$ (Ethyl Acetate/Cyclohexane, 1:1). $[\alpha]_{D}^{20}=-109.9$ (c 1.0, $\left.\mathrm{CHCl}_{3}\right) .{ }^{1} \mathrm{H}$ NMR (400 MHz, $\left.\mathrm{CDCl}_{3}\right): \delta 8.11-7.33(\mathrm{~m}, 15 \mathrm{H}, \mathrm{H}$ arom), 7.24-7.16 (m, 1H, H-3), 5.67 (dd, $J=10.3,4.6$ Hz, 1H, H-3'), 5.59 (ddd, $J=17.2,10.2,7.0 \mathrm{~Hz}, 1 \mathrm{H}, \mathrm{H}-8), 5.50$ (d, $J=2.1 \mathrm{~Hz}, 1 \mathrm{H}$, H-1), 5.47 (d, $J=7.9 \mathrm{~Hz}, 1 \mathrm{H}, \mathrm{H}-6), 5.45$ (d, $J=8.0 \mathrm{~Hz}, 1 \mathrm{H}, \mathrm{H}-2$ '), 5.18 (dt, $J=5.1$, $1.1 \mathrm{~Hz}, 1 \mathrm{H}, \mathrm{H}-10 \mathrm{a}), 5.17-5.12$ (m, 1H, H-10b), 5.09 (d, J = 7.9 Hz, 1H, H-1'), 4.74 (d, $J=1.3 \mathrm{~Hz}, 1 \mathrm{H}, \mathrm{H}-7 \mathrm{a}), 4.73-4.70$ (m, 1H, H-7b), 4.68 (d, $J=4.1 \mathrm{~Hz}, 1 \mathrm{H}, \mathrm{H}-4$ '), 4.48 (d, $J=5.7 \mathrm{~Hz}, 1 \mathrm{H}, \mathrm{H}-7 \mathrm{~b}), 4.46$ (d, $\left.J=4.9 \mathrm{~Hz}, 1 \mathrm{H}, \mathrm{H}-5^{\prime}\right), 4.43$ (t, $J=5.2 \mathrm{~Hz}, 1 \mathrm{H}$, H-6’b), 3.26 (d, $J=6.7 \mathrm{~Hz}, 1 \mathrm{H}, \mathrm{H}-9), 2.30$ (s, 3H, SAc). ${ }^{13} \mathrm{C} \mathrm{NMR}\left(101 \mathrm{MHz}, \mathrm{CDCl}_{3}\right)$ : $\delta 192.74$ (SAc), 166.20 ( $\left.\mathrm{CH}_{3} \underline{\mathrm{CO}}\right), 165.41\left(\mathrm{CH}_{3} \underline{\mathrm{CO}}\right), 165.16\left(\mathrm{CH}_{3} \underline{\mathrm{CO}}\right), 162.63(\mathrm{C}-11)$, 147.31 (C-3), 133.88-128.57 (C arom), 132.83 (C-8), 125.39 (C-5), 118.64 (C-10), 116.90 (C-6), 104.35 (C-4), 96.59 (C-1), 96.04 (C-1'), 72.42 (C-5'), 71.45 (C-3'), 70.17 (C-2'), 68.91 (C-7), 63.62 (C-6'), 46.53 (C-4'), 44.91 (C-9), 30.78 (SAc). HRMS (ESI): $m / z$ Calcd. for $\mathrm{C}_{39} \mathrm{H}_{34} \mathrm{O}_{12} \mathrm{SNa}[\mathrm{M}+\mathrm{Na}]^{+} 749.1669$, found 749.1689 (-3.4 ppm).

\subsubsection{2',3',6'-Tri-O-benzoyl-4'-azido-4'-deoxy gentiopicroside (12c)}

The protected triflate residue 12 (39 $\mathrm{mg}, 0.05 \mathrm{mmol}, 1.0$ equiv.) was dissolved in anhydrous DMF (3 mL), and then sodium azide (6.4 mg, $0.1 \mathrm{mmol}, 2.0$ equiv.) was added. This reaction mixture was stirred at room temperature for $1 \mathrm{~h}$. The reaction mixture was diluted with Ethyl Acetate $(5 \mathrm{~mL})$, washed with water $(5 \mathrm{~mL})$. The separated aqueous layer was washed with Ethyl Acetate $(2 \times 5 \mathrm{~mL})$. The combined organic layers were dried over anhydrous magnesium sulfate and concentrated in vacuum. The crude product was purified by column chromatography (Ethyl Acetate / Cyclohexane, 1:2) to give compound 12c (28mg, 83\%) as a white foam. $R_{\mathrm{f}}=0.39$ (Ethyl Acetate/Cyclohexane, 1:1). $[\alpha]_{D}^{20}=-180.9\left(\mathrm{c} 1.0, \mathrm{CHCl}_{3}\right) .{ }^{1} \mathrm{H} \mathrm{NMR}(400 \mathrm{MHz}$, $\left.\mathrm{CDCl}_{3}\right): \delta 8.13-7.34(\mathrm{~m}, 15 \mathrm{H}, \mathrm{H}$ arom), 7.22-7.14 (m, 1H, H-3), 5.72 (dd, $J=10.4$, 8.0 Hz, 1H, H-2'), 5.65-5.57 (m, 1H, H-8), 5.57-5.53 (m, 1H, H-3'), 5.51 (d, J = 2.1 Hz, 1H, H-1), 5.48-5.42 (m, 1H, H-6), 5.19-5.15 (m, 1H, H-10a), 5.14 (d, J=1.2 Hz, 1H, H-10b), 5.03 (d, $\left.J=8.0 \mathrm{~Hz}, 1 \mathrm{H}, \mathrm{H}-1^{\prime}\right), 4.71-4.68$ (m, 1H, H-7a), 4.68-4.63 (m, 
1H, H-6'a), 4.54 (dd, $J=11.4,6.7 \mathrm{~Hz}, 1 \mathrm{H}, \mathrm{H}-6$ 'b), 4.40 (d, $J=17.4 \mathrm{~Hz}, 1 \mathrm{H}, \mathrm{H}-7 \mathrm{~b}$ ), 4.35 (dd, $J=3.6,1.2 \mathrm{~Hz}, 1 \mathrm{H}, \mathrm{H}-4^{\prime}$ ) , 4.23-4.06 (m, 1H, H-5'), 3.25 (d, J = 6.8 Hz, 1H, H-9). ${ }^{13} \mathrm{C}$ NMR (101 MHz, $\mathrm{CDCl}_{3}$ ): $\delta 166.22$ (PhC्O), 165.81 (PhCOO), 165.15 (PhCுO), 162.72 (C-11), 147.27 (C-3), 134.05-128.34 (C arom), 132.87 (C-8), 125.34 (C-5), 118.68 (C-10), 117.00 (C-6), 104.43 (C-4), 96.17 (C-1'), 96.00 (C-1), 73.21 (C-3’), 71.60 (C-5'), 68.95 (C-7), 68.85 (C-2'), 62.87 (C-6'), 60.49 (C-4'), 44.96 (C-9). HRMS (ESI): $m / z$ Calcd. for $\mathrm{C}_{37} \mathrm{H}_{31} \mathrm{~N}_{3} \mathrm{O}_{11} \mathrm{Na}[\mathrm{M}+\mathrm{Na}]^{+}$716.1856, found 716.1853 (0.2 ppm).

\subsubsection{2',3',6'-Tri-O-benzoyl-4'-fluoro-4'-deoxy gentiopicroside (12d)}

The tetrabutylammonium fluoride (1M in THF) $(0.6 \mathrm{~mL}, 0.60 \mathrm{mmol}, 10.0$ equiv.) was slowly added to a solution of the protected triflate residue $(48 \mathrm{mg}, 0.06 \mathrm{mmol}, 1.0$ equiv.) in anhydrous THF $(3 \mathrm{~mL})$ at $0{ }^{\circ} \mathrm{C}$. The reaction mixture was then stirred at room temperature for $2 \mathrm{~h}$, diluted with $\mathrm{CH}_{2} \mathrm{Cl}_{2}(5 \mathrm{~mL})$, and washed with $1 \mathrm{M} \mathrm{HCl}$ (3 $\mathrm{mL})$. The combined aqueous phases were extracted once with $\mathrm{CH}_{2} \mathrm{Cl}_{2}(2 \times 5 \mathrm{~mL})$, and the combined organic phases washed with saturated sodium hydrogen carbonate (5 $\mathrm{mL})$, water $(5 \mathrm{~mL})$, dried over anhydrous magnesium sulfate and concentrated under vacuum. The residue was purified by flash column chromatography (Ethyl Acetate/Cyclohexane, 1:3) to give 12d (16 mg, 40\% in two steps) as white foam. $\mathrm{R}_{\mathrm{f}}=$

0.41 (Ethyl Acetate/Cyclohexane, 2:3). $[\alpha]_{D}^{20}=-88.0\left(\right.$ c $\left.1.0, \mathrm{CHCl}_{3}\right) .{ }^{1} \mathrm{H} \mathrm{NMR}(400$ $\left.\mathrm{MHz}, \mathrm{CDCl}_{3}\right): \delta 8.17-7.31(\mathrm{~m}, 15 \mathrm{H}, \mathrm{H}$ arom), $7.21(\mathrm{~s}, 1 \mathrm{H}, \mathrm{H}-3), 5.76(\mathrm{dd}, J=10.2$, $8.4 \mathrm{~Hz}, 1 \mathrm{H}, \mathrm{H}-3$ '), 5.60 (ddd, $J=17.4,10.3,7.1 \mathrm{~Hz}, 1 \mathrm{H}, \mathrm{H}-8), 5.54$ (d, J=1.6 Hz, 1H, H-1), 5.45 (s, 1H, H-6), 5.44-5.33 (m, 1H, H-2'), 5.26-5.18 (m, 1H, H-10a), 5.17 (s, 1H, H-4'), 5.14-5.07 (m, 1H, H-10b), 4.77-4.69 (m, 1H, H-1'), 4.70-4.63 (m, 2H, H-6'a, H-7a), 4.58 (dd, $J=11.3,6.8 \mathrm{~Hz}, 1 \mathrm{H}, \mathrm{H}-7 \mathrm{~b}), 4.39$ (d, $J=17.2 \mathrm{~Hz}, 1 \mathrm{H}, \mathrm{H}-7 \mathrm{~b})$, 4.28-4.10 (m, 1H, H-5'), 3.26 (d, J=6.8 Hz, 1H, H-9). ${ }^{13} \mathrm{C}$ NMR (101 MHz, $\mathrm{CDCl}_{3}$ ): $\delta$ 166.19-165.11 (3×PhCO), 162.68 (C-11), 147.29 (C-3), 133.88-128.68 (C arom), 132.85 (C-8), 125.34 (C-5), 118.68 (C-10), 116.97 (C-6), 104.41 (C-4), 96.03 (C-1'), 95.96 (C-1), 87.08 (C-4'), 85.21 (C-4'), 71.98 (C-5'), 71.96 (C-5'), 71.80 (C-2'), 68.92 (C-7), 68.54 (C-3'), 61.85 (C-6'), 61.80 (C-6'), 44.95 (C-9). ${ }^{19}$ F NMR (376 
$\mathrm{MHz}, \mathrm{CDCl}_{3}$ ): $\delta$-74.36. HRMS (ESI): $m / z$ Calcd. for $\mathrm{C}_{37} \mathrm{H}_{31} \mathrm{FO}_{11} \mathrm{Na}[\mathrm{M}+\mathrm{Na}]^{+}$ 693.1748, found $693.1761(-2.6 \mathrm{ppm})$.

\subsubsection{2'-O-benzoyl-4'-thio-4'-deoxy gentiopicroside (13b)}

Dibutyltin oxide (110.0 mg, $0.44 \mathrm{mmol}, 2.0$ equiv.) was added to a solution of the globe protected compound $\mathbf{1 2 b}(158.6 \mathrm{mg}, 0.22 \mathrm{mmol}, 1.0$ equiv.) in anhydrous methanol $(15 \mathrm{~mL})$. The mixture was heated under reflux at $70{ }^{\circ} \mathrm{C}$. The progress of the reaction was monitored with thin layer chromatography. Upon completion of the reaction, the mixture was evaporated to give a residue. Purification of the residue by flash column chromatography $\left(\mathrm{CH}_{2} \mathrm{Cl}_{2} / \mathrm{MeOH}, 90: 10\right)$ afforded the iodole derivative 13b $(67.7 \mathrm{mg}, 65 \%)$ as white foam. $\mathrm{R}_{\mathrm{f}}=0.39(\mathrm{DCM} / \mathrm{MeOH}, 9: 1) . \quad[\alpha]_{D}^{20}=-155.6(\mathrm{c}$ 1.0, MeOH). ${ }^{1} \mathrm{H}$ NMR (400 MHz, MeOD): $\delta$ 8.10-7.47 (m, 5H, H arom), 7.21-7.11 (s, 1H, H-3), 5.84-5.69 (m, 2H, H-1, H-8), 5.63 (m, $J=2.4 \mathrm{~Hz}, 1 \mathrm{H}, \mathrm{H}-6), 5.35$ (dd, $J=$ 9.8, 8.0 Hz, 1H, H-2'), 5.28-5.17 (m, 2H, H-10a, H-10b), 5.01 (d, J = 8.0 Hz, 1H, H-1'), 4.82 (dd, $J=4.0,0.9$ Hz, 1H, H-7a), 4.69-4.57 (m, 1H, H-7b), 4.19 (dd, $J=9.8$, 4.5 Hz, 1H, H-3'), 4.10-4.02 (m, 1H, H-5'), 3.95 (dd, J = 11.4, 7.1 Hz, 1H, H-6'a), 3.85 (dd, $J=11.4,4.8$ Hz, 1H, H-6’b), 3.58 (dd, $J=4.6,1.7$ Hz, 1H, H-4'), 3.37-3.32 (m, 1H, H-9). ${ }^{13} \mathrm{C}$ NMR (101 MHz, MeOD): $\delta 167.11$ (C arom), 165.36 (C-11), 149.07 (C-3), 134.59 (C-8), 130.87-129.73 (C arom), 126.46 (C-5), 118.25 (C-10), 118.08 (C-6), 105.01 (C-4), 98.22 (C-1'), 97.59 (C-1), 76.72 (C-5'), 73.40 (C-2’), 71.74 (C-3'), 70.32 (C-7), 63.53 (C-6'), 46.05 (C-9), 45.75 (C-4'). HRMS (ESI): m/z Calcd. for $\mathrm{C}_{16} \mathrm{H}_{20} \mathrm{SO}_{8} \mathrm{Na}[\mathrm{M}+\mathrm{Na}]^{+} 499.1039$, found 499.1035 (0.4 ppm).

\subsubsection{4'-azido-4'-deoxy gentiopicroside (13c)}

Dibutyltin oxide ( $80.0 \mathrm{mg}, 0.32 \mathrm{mmol}, 2.0$ equiv.) was added to a solution of the globe protected compound 12c (109.4 mg, $0.16 \mathrm{mmol}, 1.0$ equiv.) in anhydrous methanol $(15 \mathrm{~mL})$. The mixture was heated under reflux at $70{ }^{\circ} \mathrm{C}$. The progress of the reaction was monitored with thin layer chromatography. Upon completion of the reaction, the mixture was evaporated to give a residue. Purification of the residue by flash column chromatography $\left(\mathrm{CH}_{2} \mathrm{Cl}_{2} / \mathrm{MeOH}, 90: 10\right)$ afforded the iodole derivative

$13 \mathrm{c}(67.7 \mathrm{mg}, 83 \%)$ as white foam. $\mathrm{R}_{\mathrm{f}}=0.39(\mathrm{DCM} / \mathrm{MeOH}, 9: 1) .[\alpha]_{D}^{20}=-155.6(\mathrm{c}$ 
1.0, MeOH). ${ }^{1} \mathrm{H}$ NMR (400 MHz, MeOD): $\delta 7.50$ (t, $J=1.4 \mathrm{~Hz}, 1 \mathrm{H}, \mathrm{H}-3$ ), 5.80 (ddd, $J=17.2,10.3,6.9 \mathrm{~Hz}, 1 \mathrm{H}, \mathrm{H}-8), 5.69(\mathrm{ddd}, J=3.7,2.7,1.3 \mathrm{~Hz}, 1 \mathrm{H}, \mathrm{H}-6), 5.65$ (d, $J=$ $2.8 \mathrm{~Hz}, 1 \mathrm{H}, \mathrm{H}-1), 5.37-5.28$ (m, 1H, H-10a), 5.28-5.24 (m, 1H, H-10b), 5.14 (ddt, $J=$ 17.6, 2.6, 1.3 Hz, 1H, H-7a), 5.05 (ddt, $J=17.6,3.6,1.2 \mathrm{~Hz}, 1 \mathrm{H}, \mathrm{H}-7 \mathrm{~b}), 4.65$ (d, $J=$ $\left.7.8 \mathrm{~Hz}, 1 \mathrm{H}, \mathrm{H}-1^{\prime}\right), 3.99-3.90$ (m, 1H, H-4'), 3.83 (dd, $J=9.6,3.9 \mathrm{~Hz}, 1 \mathrm{H}, \mathrm{H}-3$ '), 3.79-3.75 (m, 1H, H-6'a), 3.74 (d, J = 5.3 Hz, 1H, H-6'b), 3.72-3.68 (m, 1H, h-5'), 3.57-3.47 (m, 1H, H-2'), 3.40-3.35 (m, 1H, H-9). ${ }^{13} \mathrm{C}$ NMR (101 MHz, MeOD): $\delta$ 166.23 (C-11), 150.47 (C-3), 134.95 (C-8), 126.92 (C-5), 118.48 (C-10), 117.26 (C-6), 104.97 (C-4), 100.72 (C-1'), 98.52 (C-1), 75.35 (C-3’), 75.13 (C-5'), 71.94 (C-2’), 70.88 (C-7), 63.99 (C-4'), 62.33 (C-6'), 46.58 (C-9). HRMS (ESI): m/z Calcd. for $\mathrm{C}_{16} \mathrm{H}_{19} \mathrm{~N}_{3} \mathrm{O}_{8} \mathrm{Na}[\mathrm{M}+\mathrm{Na}]^{+}$404.1070, found 404.1073 (-0.3 ppm).

\subsubsection{4'-fluoro-4'-deoxy gentiopicroside (13d)}

Dibutyltin oxide $(69.7 \mathrm{mg}, 0.28 \mathrm{mmol}, 2.0$ equiv.) was added to a solution of the globe protected compound 12d (94.0 mg, $0.14 \mathrm{mmol}, 1.0$ equiv.) in anhydrous methanol $(15 \mathrm{~mL})$. The mixture was heated under reflux at $70{ }^{\circ} \mathrm{C}$. The progress of the reaction was monitored with thin layer chromatography. Upon completion of the reaction, the mixture was evaporated to give a residue. Purification of the residue by flash column chromatography $\left(\mathrm{CH}_{2} \mathrm{Cl}_{2} / \mathrm{MeOH}, 90: 10\right)$ afforded the iodole derivative 13d $(21.0 \mathrm{mg}, 42 \%)$ as white foam. $\mathrm{R}_{\mathrm{f}}=0.51$ (Ethyl Acetate/MeOH, 5:1). $[\alpha]_{D}^{20}=$ -151.5 (c 1.0, MeOH). ${ }^{1} \mathrm{H}$ NMR (400 MHz, MeOD): $\delta 7.50$ (d, $J=1.3 \mathrm{~Hz}, 1 \mathrm{H}, \mathrm{H}-3$ ), 5.80 (ddd, $J=17.2,10.3,6.9 \mathrm{~Hz}, 1 \mathrm{H}, \mathrm{H}-8), 5.68$ (s, 1H, H-6), 5.68 (s, 1H, H-1), 5.34-5.28 (m, 1H, H-10a), 5.28-5.23 (m, 1H, H-10b), 5.13 (ddt, $J=17.6,2.5,1.2 \mathrm{~Hz}$, 1H, H-7a), 5.09-4.99 (m, 1H, H-7b), 4.77 (dd, J = 35.4, 1.9 Hz, 1H, H-4'), 4.70 (dd, $J$ = 7.2, 1.8 Hz, 1H, H-1'), 3.83-3.78 (m, 1H, H-6'a), 3.77 (s, 1H, H-6'b), 3.71-3.66 (m, 1H, H-5'), 3.66-3.55 (m, 1H, H-3'), 3.55-3.46 (m, 1H, H-2'), 3.43-3.37 (m, 1H, H-9).

${ }^{13} \mathrm{C}$ NMR (101 MHz, MeOD): $\delta 166.38$ (C-11), 150.65 (C-3), 135.09 (C-8), 127.10 (C-5), 118.67 (C-10), 117.41 (C-6), 105.13 (C-4), 100.61 (C-1'), 98.72 (C-1), 91.24 (C-4'), 89.45 (C-4'), 75.89 (C-5'), 75.71 (C-5'), 73.70 (C-3’), 73.52 (C-3’), 72.07 (C-2'), 71.03 (C-7), 61.46 (C-6'), 61.41 (C-6'), 46.76 (C-9). HRMS (ESI): m/z Calcd. 
for $\mathrm{C}_{16} \mathrm{H}_{19} \mathrm{FO}_{8} \mathrm{Na}[\mathrm{M}+\mathrm{Na}]^{+}$381.0962, found 381.0960 (0.2 ppm).

\subsubsection{2',3',6'-Tri-O-benzoyl-4'-S-acetyl-4'-thio-4'-deoxy gentiopicroside (14a)}

Potassium thioacetate ( $17.5 \mathrm{mg}, 0.15 \mathrm{mmol}, 3.0$ equiv.) was added to a solution of the protected triflate residue (41.0 mg, $0.05 \mathrm{mmol}, 1.0$ equiv.) in anhydrous DMF (3 $\mathrm{mL}$ ). After stirring at room temperature for $2 \mathrm{~h}$, the mixture was diluted with Ethyl Acetate $(2 \times 5 \mathrm{~mL})$, washed with brine $(5 \mathrm{~mL})$. The organic phase was dried over anhydrous magnesium sulfate and concentrated in vacuum. Purification of the residue by flash column chromatography (Ethyl Acetate/cyclohexane, 1:2) afforded the thiolacetate derivative 14a $\left(28 \mathrm{mg}, 76 \%\right.$ in two steps). $\mathrm{R}_{\mathrm{f}}=0.29$ (Ethyl Acetate/Cyclohexane, 1:2). $[\alpha]_{D}^{20}=-40.9\left(\mathrm{c} 1.0, \mathrm{CHCl}_{3}\right) .{ }^{1} \mathrm{H} \mathrm{NMR}\left(400 \mathrm{MHz}, \mathrm{CDCl}_{3}\right)$ : $\delta$ 8.18-7.32 (m, 15H, H arom), 7.19 (s, 1H, H-3), 5.73 (dd, $J=10.8,9.7$ Hz, 1H, H-3'), 5.56 (ddd, $J=17.2,10.1,7.0 \mathrm{~Hz}, 1 \mathrm{H}, \mathrm{H}-8), 5.48$ (d, $J=2.2 \mathrm{~Hz}, 1 \mathrm{H}, \mathrm{H}-1), 5.42$ (d, $J=$ $8.1 \mathrm{~Hz}, 1 \mathrm{H}, \mathrm{H}-2$ ') 5.40 (d, $J=8.2 \mathrm{~Hz}, 1 \mathrm{H}, \mathrm{H}-6$ ), 5.20-5.14 (m, 1H, H-10a), 5.13 (d, $J$ $=10.4 \mathrm{~Hz}, 1 \mathrm{H}, \mathrm{H}-10 \mathrm{~b}), 5.10$ (d, $J=8.2 \mathrm{~Hz}, 1 \mathrm{H}, \mathrm{H}-1$ '), 4.75-4.68 (m, 1H, H-6'a), 4.68-4.63 (m, 1H, H-7a), 4.60 (dd, $J=12.2,4.7$ Hz, 1H, H-6’b), 4.45-4.33 (m, 1H, H-7b), 4.23-4.14 (m, 1H, H-5'), 4.14-4.02 (m, J=11.2, 1H, H-4'), 3.21 (d, J=6.9 Hz, 1H, H-9), 2.20 (s, 3H, SAc). ${ }^{13} \mathrm{C}$ NMR (101 MHz, $\mathrm{CDCl}_{3}$ ): $\delta 192.71$ (SAc), 166.37 (Phㅁ), 165.77 (Phㅁ), 165.16 (PhCOO), 162.69 (C-11), 147.45 (C-3), 133.84-128.60 (C arom), 132.84 (C-8), 125.44 (C-5), 118.68 (C-10), 116.80 (C-6), 104.34 (C-4), 96.09 (C-1'), 95.87 (C-1), 73.61 (C-5'), 72.37 (C-2'), 71.52 (C-3'), 68.92 (C-7), 63.73 (C-6'), 44.94 (C-9), 44.69 (C-4'), 30.92 (SAc). HRMS (ESI): m/z Calcd. for $\mathrm{C}_{39} \mathrm{H}_{34} \mathrm{O}_{12} \mathrm{SNa}[\mathrm{M}+\mathrm{Na}]^{+}$749.1669, found 749.1663 (-0.5 ppm).

\subsubsection{2',3',6'-Tri-O-benzoyl-4'-azido-4'-deoxy gentiopicroside (14b)}

The protected triflate residue (38.6 $\mathrm{mg}, 0.048 \mathrm{mmol}, 1.0$ equiv.) was dissolved in anhydrous DMF (3 mL), and then sodium azide (6.3 mg, $0.1 \mathrm{mmol}, 2.0$ equiv.) was added. This reaction mixture was stirred at room temperature for $1 \mathrm{~h}$. The reaction mixture was diluted with Ethyl Acetate $(5 \mathrm{~mL})$, washed with water $(5 \mathrm{~mL})$. The separated aqueous layer was washed with Ethyl Acetate $(2 \times 5 \mathrm{~mL})$. The combined organic layers were dried over anhydrous magnesium sulfate and concentrated in 
vacuum. The crude product was purified by column chromatography (Ethyl Acetate/Cyclohexane, 1:2) to give compound $\mathbf{1 4 b}(31.5 \mathrm{mg}, 78 \%$ in two steps) as a white foam. $\mathrm{R}_{\mathrm{f}}=0.38$ (Ethyl Acetate/Cyclohexane, 1:1). $[\alpha]_{D}^{20}=-53.0\left(\mathrm{c} 1.0, \mathrm{CHCl}_{3}\right.$ ). ${ }^{1} \mathrm{H}$ NMR (400 MHz, $\mathrm{CDCl}_{3}$ ): $\delta$ 8.19-7.33 (m, 15H, $\mathrm{H}$ arom), 7.23-7.14 (m, 1H, H-3), 5.69 (t, $J=9.8 \mathrm{~Hz}, 1 \mathrm{H}, \mathrm{H}-3$ ') 5.57 (ddd, $J=17.2$, 10.2, $7.0 \mathrm{~Hz}, 1 \mathrm{H}, \mathrm{H}-8$ ), 5.47 (d, $J=$ $2.3 \mathrm{~Hz}, 1 \mathrm{H}, \mathrm{H}-1), 5.45-5.41$ (m, 1H, H-6), 5.38 (dd, $J=9.9,8.1 \mathrm{~Hz}, 1 \mathrm{H}, \mathrm{H}-2$ '), 5.15 (dd, $J=4.1,1.2 \mathrm{~Hz}, 1 \mathrm{H}, \mathrm{H}-10 \mathrm{a}), 5.13-5.05$ (m, 2H, H-10b, H-1'), 4.77 (dd, $J=12.3$, $2.3 \mathrm{~Hz}, 1 \mathrm{H}, \mathrm{H}-6$ 'a), 4.72-4.61 (m, 2H, H-6’b, H-7a), 4.41 (d, J = 17.4 Hz, 1H, H-7b), 3.94 (t, $J=9.9$ Hz, 1H, H-4'), 3.83 (ddd, $J=10.2,4.1,2.3 \mathrm{~Hz}, 1 \mathrm{H}, \mathrm{H}-5$ '), 3.20 (d, $J=$ $6.6 \mathrm{~Hz}, 1 \mathrm{H}, \mathrm{H}-9) .{ }^{13} \mathrm{C} \mathrm{NMR}\left(101 \mathrm{MHz}, \mathrm{CDCl}_{3}\right): \delta 166.21$ (PhCO), 165.61 (PhCO), 165.22 (PhCO), 162.57 (C-11), 147.38 (C-3), 133.95-128.58 (C arom), 132.73 (C-8), 125.39 (C-5), 118.75 (C-10), 116.84 (C-6), 104.36 (C-4), 96.16 (C-1), 95.92 (C-1'), 73.39 (C-3'), 73.25 (C-5'), 71.14 (C-2'), 68.90 (C-7), 63.15 (C-6'), 60.97 (C-4'), 44.91 (C-9). HRMS (ESI): $m / z$ Calcd. for $\mathrm{C}_{37} \mathrm{H}_{31} \mathrm{~N}_{3} \mathrm{O}_{11} \mathrm{Na}[\mathrm{M}+\mathrm{Na}]^{+} 716.1856$, found $716.1850(0.5 \mathrm{ppm})$.

\subsubsection{2',3',6'-Tri-O-benzoyl-4'-fluoro-4'-deoxy gentiopicroside (14c)}

To a solution of 12a (208.5 mg, $0.31 \mathrm{mmol}, 1.0$ equiv.) in anhydrous DCM (5 mL) at $-30{ }^{\circ} \mathrm{C}$ was added diethylaminosulfur trifluoride $(122 \mu \mathrm{L}, 0.93 \mathrm{mmol}, 3.0$ equiv.) and pyridine $(100 \mu \mathrm{L})$. The reaction mixture was stirred for $3 \mathrm{~h}$ at the room temperature, and quenched by addition with $\mathrm{MeOH}$ (several drops) at $0{ }^{\circ} \mathrm{C}$. The residue was diluted with Ethyl Acetate $(20 \mathrm{~mL})$, and washed with waterl $(10 \mathrm{~mL})$, washed with saturated $\mathrm{NaHCO}_{3}(10 \mathrm{~mL})$, brine $(10 \mathrm{~mL})$, dried over anhydrous magnesium sulfate and concentrated under vacuum. The residue was purified by flash column chromatography (Ethyl Acetate/Cyclohexane, 1:4) to give 14c (166.8 mg, $80 \%$ ) as white foam. $\mathrm{R}_{\mathrm{f}}=0.47$ (Ethyl Acetate/Cyclohexane, 1:2). $[\alpha]_{D}^{20}=-52.9$ (c 2.0, $\left.\mathrm{CHCl}_{3}\right) .{ }^{1} \mathrm{H} \mathrm{NMR}\left(400 \mathrm{MHz}, \mathrm{CDCl}_{3}\right): \delta 8.14-7.34(\mathrm{~m}, 15 \mathrm{H}, \mathrm{H}$ arom), 7.25-7.14 (s, $1 \mathrm{H}$, H-3), 5.84 (ddd, $J=13.8,10.0,8.9$ Hz, 1H, H-3'), 5.69-5.52 (m, 1H, H-8), 5.48 (d, $J$ $=2.3 \mathrm{~Hz}, 1 \mathrm{H}, \mathrm{H}-1), 5.45-5.35$ (m, 2H, H-6, H-2'), 5.19-5.09 (m, 3H, H-1', H-10a, H-10b), 4.93-4.78 (m, 1/2H, H-4'), 4.76 (d, J = 1.9 Hz, 1.5H, H-6' a, H-4'), 4.73-4.65 
(m, 1H, H-7a), 4.62 (ddd, $J=12.3,4.5,1.5 \mathrm{~Hz}, 1 \mathrm{H}, \mathrm{H}-6$ 'b), 4.42 (dd, $J=17.5,2.4$, $1.1 \mathrm{~Hz}, 1 \mathrm{H}, \mathrm{H}-7 \mathrm{~b}), 4.18-4.01$ (m, 1H, H-5'), 3.24-3.07 (d, 1H, H-9). ${ }^{13} \mathrm{C}$ NMR (101 $\mathrm{MHz}, \mathrm{CDCl}_{3}$ ): $\delta 166.16$ (Phㄷ), 165.50 (PhCO), 165.07 (PhCO), 162.50 (C-11), 147.30 (C-3), 133.94-128.38 (C arom), 132.63 (C-8), 125.33 (C-5), 118.76 (C-10), 116.83 (C-6), 104.34 (C-4), 96.19 (C-1), 95.88 (C-1'), 88.22 (C-4'), 86.34 (C-4'), 72.50 (C-3'), 72.07 (C-5'), 70.61 (C-2'), 68.85 (C-7), 62.33 (C-6'), 44.88 (C-9). HRMS (ESI): $m / z$ Calcd. for $\mathrm{C}_{37} \mathrm{H}_{31} \mathrm{FO}_{11} \mathrm{Na}[\mathrm{M}+\mathrm{Na}]^{+}$693.1748, found $693.1744(0.4$ ppm).

\subsubsection{4'-thio-4'-deoxy gentiopicroside (15a)}

Dibutyltin oxide (127.0 mg, $0.51 \mathrm{mmol}, 3.0$ equiv.) was added to a solution of the globe protected compound $\mathbf{1 4 a}(120.3 \mathrm{mg}, 0.17 \mathrm{mmol}, 1.0$ equiv.) in anhydrous methanol $(15 \mathrm{~mL})$. The mixture was heated under reflux at $70{ }^{\circ} \mathrm{C}$. The progress of the reaction was monitored with thin layer chromatography. Upon completion of the reaction, the mixture was evaporated to give a residue. Purification of the residue by flash column chromatography $\left(\mathrm{CH}_{2} \mathrm{Cl}_{2} / \mathrm{MeOH}, 90: 10\right)$ afforded the iodole derivative $15 \mathbf{a}(21.9 \mathrm{mg}, 47 \%)$ as white foam. $\mathrm{R}_{\mathrm{f}}=0.45(\mathrm{EtOAc} / \mathrm{MeOH}, 5: 1) .[\alpha]_{D}^{20}=-145.3(\mathrm{c}$ 1.0, MeOH). ${ }^{1} \mathrm{H}$ NMR (400 MHz, MeOD): $\delta$ 7.52-7.49 (m, 1H, H-3), 5.94-5.74 (m, 1H, H-8), 5.76-5.62 (m, 2H, H-1, H-6), 5.38-5.22 (m, 2H, H-10a, H-10b), 5.19-5.01 (m, 2H, H-7a, H-7b), 4.74 (d, J = 7.9 Hz, 1H, H-1'), 4.09-3.95 (m, 1H, H-6'a), 3.89-3.78 (m, 1H, H-6'b), 3.48 (m, $J=12.9,7.7,4.4,2.6$ Hz, 1H, H-5'), 3.38-3.36 (m, 1H, H-9),3.36-3.30 (m, 1H, H-3'), 3.27-3.16 (t, 1H, H-2'), 2.83-2.71 (t, 1H, H-4'). ${ }^{13} \mathrm{C}$ NMR (101 MHz, MeOD): $\delta 166.22$ (C-11), 150.58 (C-3), 134.97 (C-8), 127.00 (C-5), 118.50 (C-10), 117.17 (C-6), 104.93 (C-4), 100.12 (C-1'), 98.45 (C-1), 79.78 (C-5'), 78.91 (C-3'), 75.54 (C-2'), 70.86 (C-7), 63.22 (C-6'), 46.60 (C-9), 43.26 (C-4'). HRMS (ESI): $m / z$ Calcd. for $\mathrm{C}_{16} \mathrm{H}_{20} \mathrm{SO}_{8} \mathrm{Na}[\mathrm{M}+\mathrm{Na}]^{+} 395.0777$, found 395.0774 (0.3 ppm).

\subsubsection{2',3',6'-Tri-O-benzoyl-4',5'-olefin gentiopicroside (16)}

The tetrabutylammonium fluoride (TBAF, $1 \mathrm{M}$ in THF) $(0.37 \mathrm{~mL}, 0.37 \mathrm{mmol}, 5.0$ equiv.) was slowly added to a solution of the protected triflate residue $(59.0 \mathrm{mg}, 0.074$ 
mmol, 1.0 equiv. $)$ in anhydrous $\operatorname{THF}(3 \mathrm{~mL})$ at $0{ }^{\circ} \mathrm{C}$. The reaction mixture was then stirred at room temperature for $2 \mathrm{~h}$, diluted with Ethyl Acetate $(5 \mathrm{~mL})$, and washed with $1 \mathrm{M} \mathrm{HCl}(3 \mathrm{~mL})$. The combined aqueous phases were extracted once with Ethyl Acetate $(2 \times 5 \mathrm{~mL})$, and the combined organic phases washed with saturated sodium hydrogen carbonate $(5 \mathrm{~mL})$, water $(5 \mathrm{~mL})$, dried over anhydrous magnesium sulfate and concentrated under vacuum. The residue was purified by flash column chromatography (Ethyl Acetate/Cyclohexane, 1:2) to give 16 (19 mg, 40\% in two steps) as a white foam. $\mathrm{R}_{\mathrm{f}}=0.28$ (Ethyl Acetate/Cyclohexane, 1:2). $[\alpha]_{D}^{20}=-54.3(\mathrm{c}$ 1.0, $\left.\mathrm{CHCl}_{3}\right) .{ }^{1} \mathrm{H}$ NMR $\left(400 \mathrm{MHz}, \mathrm{CDCl}_{3}\right): \delta 8.14-7.42(\mathrm{~m}, 15 \mathrm{H}, \mathrm{H}$ arom), $7.40(\mathrm{~d}, J=$ $7.5 \mathrm{~Hz}, 1 \mathrm{H}, \mathrm{H}-3), 5.70$ (dd, $J=3.6,0.9 \mathrm{~Hz}, 1 \mathrm{H}, \mathrm{H}-1^{\prime}$ ), 5.56 (dd, $J=3.3,2.2 \mathrm{~Hz}, 1 \mathrm{H}$, H-2'), 5.54 (d, J=3.8 Hz, 1H, H-3'), 5.53-5.50 (m, 1H, H-8), 5.49 (d, J=3.3 Hz, 1H, H-4'), 5.46 (d, $J=3.7 \mathrm{~Hz}, 1 \mathrm{H}, \mathrm{H}-1$ ), 5.36 (d, $J=3.0 \mathrm{~Hz}, 1 \mathrm{H}, \mathrm{H}-6$ ), 5.13 (dd, $J=2.0$, $1.2 \mathrm{~Hz}, 1 \mathrm{H}, \mathrm{H}-10 \mathrm{a}), 5.09$ (dt, $J=9.7,1.1 \mathrm{~Hz}, 1 \mathrm{H}, \mathrm{H}-10 \mathrm{~b}), 4.96-4.87$ (m, 1H, H-6' a), 4.87-4.76 (m, 2H, H -6’b, H-7a), 4.69-4.59 (m, 1H, H-7b), 3.23-3.14 (m, 1H, H-9). ${ }^{13} \mathrm{C}$ NMR (101 MHz, $\mathrm{CDCl}_{3}$ ): $\delta 166.02$ (PhC्O), 165.77 (PhCO), 165.05 (PhCO), 163.08 (C-11), 149.08 (C-5'), 148.93(C-3), 133.94-128.50 (C arom), 132.48 (C-8), 126.02 (C-5), 119.35 (C-10), 115.96 (C-6), 104.10 (C-4), 99.18 (C-4'), 96.39 (C-1), 92.62 (C-1'), 69.16 (C-7), 68.44 (C-2'), 65.56 (C-3'), 63.24 (C-6’), 45.28 (C-9). HRMS (ESI): $\mathrm{m} / \mathrm{z}$ Calcd. for $\mathrm{C}_{37} \mathrm{H}_{30} \mathrm{O}_{11} \mathrm{Na}[\mathrm{M}+\mathrm{Na}]:$ 673.1679, found $673.1680(0.2$ ppm).

4.3. Cytopathic effect (CPE) reduction assay

The assay was performed as described by Noah et al. with some modifications [37]. MDCK cells were seeded into 96-well plates, incubated overnight and infected with influenza virus (MOI 1/4 0.1) suspended in DMEM supplemented with $1 \% \mathrm{FBS}$, containing test compound and $2 \mathrm{mg} / \mathrm{mL}$ TPCK-treated trypsin, with a final DMSO concentration of $1 \%$ in each well. After $40 \mathrm{~h}$ of incubation, CellTiterGlo reagent (Promega Corp., Madison, WI, USA) was added and the plates were read using a plate reader (Tecan Infinite M2000 PRO ${ }^{\mathrm{TM}}$; Tecan Group Ltd., Mannedorf, Switzerland). 


\subsection{Cytotoxicity test}

Cells grown in 96-well plates overnight were cultured in 1\% FBS with increasing amounts of the test compounds for $40 \mathrm{~h}$. Cytotoxicity was assessed with the CellTiter-Glo assay described as above.

\section{Acknowledgements}

We sincerely thank the China Scholarship Council for a Ph.D. fellowship to S. Wu.

The work was supported by the University Pierre \& Marie Curie, the Centre National de la Recherche Scientifique (CNRS), Program for Changjiang Scholars and Innovative Research Team in University (No. IRT_15R55), the Science Foundation of Northwest University (No. 15NW17), Scientific Research Program Funded by Shaanxi Provincial Education Department (No. 16JK1778), the International Science \& Technology Cooperation Program of Shaanxi Province (No. 2016KW-003) and Opening Foundation of Key Laboratory of Resource Biology and Biotechnology in Western China (Northwest University), Ministry of Education.

\section{Appendix A. Supplementary data}

Supplementary data related to this article can be found at http://

\section{References}

[1] G. A. Poland, R. M. Jacobson, P. V. Targonski, Vaccine. 25 (2007) 3057-3061.

[2] A. C. Hurt, H. T. Ho, I. Barr, Expert Rev. Anti-Infect. Ther. 4 (2006) 795-805.

[3] D. Lavanchy, Clin. Microbiol. Infect. 17 (2011) 107-115.

[4] E. Palumbo, Ther. Adv. Chronic Dis. 2 (2011) 39-45.

[5] F. Poordad, D. Dieterich, J. Viral Hepatitis. 19 (2012) 449-524.

[6] J. M. Pawlotsky, Adv. Pharmacol. 67 (2013) 169-215.

[7] D. J. Newman, G. M. Cragg, J. Nat. Prod. 75 (2012) 311-335.

[8] J. Clardy, C. Walsh, Nature. 432 (2004) 829-837.

[9] R. Bade, H. F. Chan, J. Reynisson, Eur. J. Med. Chem. 45 (2010) 5646-5652.

[10] a) S. Xiao, Q. Wang, L. Si, X. Zhou, Y. Zhang, L. Zhang, D. Zhou, Eur. J. Med. Chem. 124 (2016) 1-9. b) M. Bassetto, P. Leyssen, J. Neyts, M. M. Yerukhimovich, D. N. Frick, A. Brancale, Eur. J. Med. Chem. 123 (2016) 31-47. c) M. Camarasa, R. P. Bellacasa, A. L. Gonzalez, R. Ondono, R. Estrada, S. Franco, R. Badia, J. Este, M. Martinez, J. Teixido, B. Clotet, J. I. Borrell, Eur. J. Med. Chem. 115 (2016) 463-483. d) T. A. Fernandes, D. Manvar, J. L. O. Domingos, A. Basu, D. B. Nichols, N. Kaushik-Basu, P. R. R. Costa, Eur. J. Med. Chem. 112 (2016) 33-38. 
[11] a) K. Hase, J. Li, P. Basnet, Chem. Pharm. Bull. 45 (1997) 1823-1827. b) N. Ozturk, S. Korkmaz, Y. Ozturk, Planta. Med. 72 (2006) 289-294. c) N. Ozturk, K. H. Baser, S. Aydin, Phytother. Res. 16 (2002) 627-631.

[12] L. Chen, J. Liu, X. Zhang, Neyropharmacology. 54 (2008) 1175-1181.

[13] K. Mustafayeva, C. D. Giorgio, R. Elias, J. Nat. Prod. 73 (2010) 99-103.

[14] X. Tang, Q. Yang, F. Yang, J. Gong, H. Han, L. Yang, Z. Wang, J. Ethnopharmacol. 194 (2016) 63-71.

[15] S. Wu, Y. Ning, Y. Zhao,W. Sun, S. Thorimbert, L. Dechoux, M. Sollogoub, Y. Zhang, Mini-Rev. Med. Chem. 17 (2017) 62-77.

[16] S. Wu, Y. Zhang, J. Agarwal, E. Mathieu, S. Thorimbert, L. Dechoux, Tetrahedron. 71 (2015) 7663-7669.

[17] F. Zhang, W. Zhang, Y. Zhang, D. P. Curran, G. Liu, J. Org. Chem. 74 (2009) 2594-2597.

[18] Y. X. Lu, Y. T. Liu, Z. J. Xu, H. Y. Li, H. L. Liu, W. L. Zhu, Expert Opinion on Drug Discovery. 7 (2012) 375-383.

[19] S. Parcell, Altern Med Rev. 7 (2002) 22-44.

[20] A. L. Simplício, J. M. Clancy , J. F. Gilmer, Molecules. 13 (2008) 519-547.

[21] W. B. Turnbull, S. A. Kalovidouris, J. F. Stoddart, Chem. Eur. J. 8 (2002) 2988-3000.

[22] J. L. O'Brien, M. Tosin, P. Murphy, Org. Lett. 3 (2001) 3353-3356.

[23] Z. C. Pei, H. D. R. Caraballo, O. Ramström, Eur. J. Org. Chem. 29 (2007) 4927-4934.

[24] M. Emmadi ,S. S. Kulkarni, J. Org. Chem. 76 (2011) 4703-4709.

[25] C. S. Rye, S. G. Withers, J. Am. Chem. Soc. 124 (2002) 9756-9767.

[26] H. Staudinger, J. Meyer, Helv. Chim. Acta. 2 (1919) 635-646.

[27] E. E. Tamelen, J. Am. Chem. Soc. 73 (1951) 5773-5774.

[28] G. Zemplén, E. Pacsu, Ber. Dtsch, Chem. Ges. 62 (1929) 1613-1614.

[29] L. Hradilová, M. Poláková, B. Dvoráková, M. Hajdúch, L. Petruš, Carbohydr. Res. 361 (2012) $1-6$.

[30] E. Repetto, C. Marino, M. L. Uhrig, O. Varela, Bioorg. \& Med. Chem. 17 (2009) 2703-2711.

[31] M. A. Shaban, A. Z. Nasr, A. E. Morgaan, Pharmazie. 55 (2000) 87-93.

[32] H. M. Liu, X. Yan, W. Li, C. Huang, Carbohydr. Res. 337 (2002) 1763-1767.

[33] A. Graziani, P. Passacantilli, G. Piancatelli, S. Tani, Tetra. Lett. 42 (2001) 3857-3860.

[34] W. Subotkowski, D. Friedrich, F. J. Weiberth, Carbohydr. Res. 346 (2011) 2323-2326.

[35] U. Sirion, S. Kasemsook, K. Suksen, P. Piyachaturawat, A. Suksamrarn, R. Saeeng, Bioorg. Med. Chem. Lett. 22 (2012) 49-52.

[36] F. Yu, Q. Wang, Z. Zhang, Y. Peng, Y. Qiu, Y. Shi, Y. Zheng, S. Xiao, H. Wang, X. Huang, L. Zhu, K. Chen, C. Zhao, C. Zhang, M. Yu, D. Sun, L. Zhang, D. Zhou, J. Med. Chem. 56 (2013) 4300-4319.

[37] J. W. Noah, W. Severson, D. L. Noah, L. Rasmussen, E. L. White, C. B. Jonsson, Antivir. Res. 73 (2007) 50-59. 


\section{Design, synthesis and biological evaluation of gentiopicroside derivatives as potential antiviral inhibitors}

Shaoping $\mathrm{Wu}^{\mathrm{a}}{ }^{\mathrm{b}}$, Lili Yang ${ }^{\mathrm{a}}$, Wenji Sun ${ }^{\mathrm{a}}$, Longlong $\mathrm{Si}^{\mathrm{d}}$, Sulong Xiao ${ }^{\mathrm{d}}$, Qi Wang ${ }^{\mathrm{d}}$, Luc Dechoux ${ }^{\mathrm{b}}$, Serge Thorimbert $^{\mathrm{b}}$, Matthieu Sollogoub ${ }^{\mathrm{b}}$, Demin Zhou ${ }^{\mathrm{d}}$, Yongmin Zhang ${ }^{\mathrm{a}, \mathrm{b}, \mathrm{c}, *}$

\footnotetext{
${ }^{a}$ Key Laboratory of Resource Biology and Biotechnology in Western China (Northwest University), Ministry of Education; Biomedicine Key Laboratory of Shaanxi Province, Northwest University, Xi'an 710069, China

${ }^{b}$ Sorbonne Universités, UPMC Univ Paris 06, Institut Parisien de Chimie Moléculaire, CNRS UMR 8232, 4 place Jussieu, 75005 Paris, France

${ }^{c}$ Institute for Interdisciplinary Research, Jianghan University, Wuhan Economic and Technological Development Zone, Wuhan 430056, China

${ }^{d}$ State Key Laboratory of Natural and Biomimetic Drugs, School of Pharmaceutical Sciences, Peking University, Beijing 100191, China
}

*Address correspondence to this author at the Sorbonne Universités, UPMC Univ Paris 06, CNRS UMR 8232, 4 place Jussieu, 75005 Paris, France. Tel: 33-1-44276153. Fax: 33-1-44275504. E-mails: yongmin.zhang@upmc.fr

Highlights:

- A novel series of gentiopicroside derivatives was designed and synthesized.

- All the newly synthesized compounds were evaluated for the inhibition of influenza virus and anti-HCV activity in vitro.

- Compound 11a, 13d and 16 displayed interesting anti-influenza virus activity.

- Compound 13d could be as new lead compound in the development of potential antiviral inhibitors. 